\title{
Article \\ On-Site Monitoring for the Stability Evaluation of a Highway Tunnel above Goaves of Multi-Layer Coal Seams
}

\author{
Guangtao Cai ${ }^{1}$, Wanghua Sui ${ }^{1, * \mathbb{D}}$, Shenglin $\mathrm{Wu}^{1,2}{ }^{1}$, Jilin Wang ${ }^{1}$ and Jiaxing Chen ${ }^{1}$ \\ 1 School of Resources and Geosciences, Institute of Mine Water Hazards Prevention and Controlling \\ Technology, China University of Mining and Technology, Xuzhou 221116, China; 0023@cumt.edu.cn (G.C.); \\ 1616@cumt.edu.cn (S.W.); wjl_cumt@163.com (J.W.); TS19010069A31TM@cumt.edu.cn (J.C.) \\ 2 CUMT Geotechnical Engineering and New Technology Development Co., Ltd., Xuzhou 221008, China \\ * Correspondence: suiwanghua@cumt.edu.cn; Tel.: +86-13952199519
}

Citation: Cai, G.; Sui, W.; Wu, S.; Wang, J.; Chen, J. On-Site Monitoring for the Stability Evaluation of a Highway Tunnel above Goaves of Multi-Layer Coal Seams. Appl. Sci. 2021, 11, 7383. https://doi.org/ 10.3390/app11167383

Received: 10 June 2021

Accepted: 6 August 2021

Published: 11 August 2021

Publisher's Note: MDPI stays neutral with regard to jurisdictional claims in published maps and institutional affiliations.

Copyright: (c) 2021 by the authors. Licensee MDPI, Basel, Switzerland. This article is an open access article distributed under the terms and conditions of the Creative Commons Attribution (CC BY) license (https:// creativecommons.org/licenses/by/ $4.0 /)$.

\begin{abstract}
This paper presents the on-site monitoring of a medium-long highway tunnel constructed above a goaf of a multi-layer coal seam, in order to evaluate and maintain safety during operation. The case study of the Tianzimiao medium-long highway tunnel in Shanxi province was conducted above a goaf of a multi-layer coal seam with typical geological and engineering conditions in China, where a total of four coal seams (seam no. 3, 8, 12, and 15) were mined out with a total thickness of up to $11 \mathrm{~m}$. Methods including data collection, engineering geological survey, drilling, geophysical prospecting, testing, and on-site monitoring were adopted, and a geo-mechanical model was established to conduct the research. Stratified monitoring was applied to investigate the individual settlement and deformation of the four layers of the goaf below, and a prediction of the possible deformation in tunnel floor ground was made based on the stratified measurements. The settlement of the tunnel sidewall, the internal stress in the fractured zone of the surrounding rock, and the deformation above the tunnel entrance were also monitored, and the monitoring data were compared with the numerical simulation results for the safety evaluation of the tunnel. The results show that the current tunnel deformation values and trend are both within the safety scope of the evaluation and prediction. The stability evaluation method for the multi-layer goaf used in this paper and the long-term on-site monitoring and timely feedback during operation is helpful to ensure the safe use of the tunnels above the goaves of multi-layer thick coal seams.
\end{abstract}

Keywords: highway tunnel; goaf of multi-layer coal seam; stratified monitoring; stability evaluation

\section{Introduction}

Geological disasters such as ground subsidence caused by coal mining have become increasingly prominent in China. According to a statistic in 2015, the area of abandoned coal mines in Shanxi province exceeded $20,000 \mathrm{~km}^{2}$, which is equivalent to one-seventh of the total land of the major coal-producing province. Of this, $6000 \mathrm{~km}^{2}$ of land suffered geological disasters caused by the subsidence of mined-out areas [1].

With the rapid construction of highways and urban highway networks in China, there has been an increasing amount of highway construction running through coal mining subsidence areas; for example, part of the expressways in Guangdong province [2], and the construction of the Outer Ring Expressway of Xuzhou, Jiangsu province [2,3], encountered geotechnical engineering problems due to passing through the goaf of coal mines. Meanwhile, research on the impact of the underlying goaf on the stability of expressways has been widely conducted in recent years [4-10]. Li et al. [11] revealed the evolution law of the surrounding rock rupture during the construction of the tunnel under the point-column goaf by using a similar model test. Huang [12] conducted research on the surrounding rock stress of a tunnel by on-site monitoring and the numerical simulation method, presenting that the secondary lining receives the contact pressure created by rheological rock. The 
rheological stress release rate is less than $7 \%$ in rock arches and more than $55 \%$ in spandrels and hances.

Mining subsidence is a complicated geological and mechanical change process, and the surface movement and deformation as well as engineering geological stability of the overburden above the goaf area are affected by various conditions, including geological conditions and mining situations [13]. The probability integral method proposed based on the random medium theory has been widely used in the mining industry in China $[14,15]$. FLAC analysis shows that the railway can subside due to the mined caves located $50 \mathrm{~m}$ to the west, although the deformation modes can vary, and the subsidence can be protected by filling the caves in Korea [16]. Considering that the stability of the goaf is a systemic problem that involves many factors, such as geology and mining, and by using similar simulation experiments and numerical simulations, recent research on the overburdened rock and surface deformation in goaf areas has obtained satisfying results [17-24]. Li et al., Cui, and Donnelly [25-27] described the analysis method for the numerical calculation of the stability of the goaf and discussed the method of construction and subsidence in the goaf and the examples applied in the engineering. Teng et al. [28] used the significance between the influence of the depth of building loads and the developing height of the crack zone to judge the stability of the foundation in the goaf area. Some scholars [29-32] carried out prediction and analysis with a focus on the effect of the remaining deformation of the goaf area on the expressway and conducted systematic research using an analysis theory on the interaction between the highway and the underlying goaf and the relevant treatment technology for the goaf.

For the deformation monitoring of a goaf, total-station instruments and optical leveling instruments, or conventional geodetic methods are generally used for monitoring localized and smaller-scale deformations of buildings or structures.

The Tianzimiao Highway Tunnel is a double-line parallel tunnel of the 307 national highway double-line reconstruction projects in Yangquan city, Shanxi province, and it is divided into the left and the right lines. The total length of the tunnel is $1707.15 \mathrm{~m}$. It is located within the boundary of the mined-out areas of the Yangquan Coal Mining Group and the Hanhegou coal mines. A total of four seams (seam no. 3, 8, 12, and 15) with a maximum cumulative thickness of up to $11 \mathrm{~m}$ were mined below the tunnel. Due to the complex geological conditions of the construction site of the Tianzimiao tunnel, the underground goaves are mainly multi-layer repetitive mining, and the mining method, depth, thickness, and final mining time are all different. The tunnel construction on the site is prone to potential geological hazards, such as settlement, deformation, and roof collapse. Ding [33] concludes that the mechanical model of the collapse medium is in accordance with the non-linear nature of the rock creep Kelvin model by using similar simulation tests and numerical simulation. Due to the goaf of the multi-layer seam beneath the site, Ding [33] forecasted the residual deformation on the site; the degree of influence of mining on the overburden deformation is a problem that needs to be solved in this study. At the same time, the final ground deformation of the site is the result of the comprehensive superposition of the deformation of the lower goaves. Therefore, the development trend of the deformation of the goaf with different depths and its contribution to the ground deformation are also very important for the study of this project. This is also the difference between this project and previous projects.

The Tianzimiao tunnel is a fortress passage of the national highway 307, with great significance in terms of its geographical location and operational functions. It was constructed with the mining method. Therefore, reliable methods and means must be used to ensure the stability and safety of the tunnel. The geological conditions and engineering conditions of the Tianzimiao tunnel project are representative to other coal mines in Shanxi province. Additionally, there has not been any useful experience at home or abroad for reference in terms of the stability and deformation prediction of the tunnel constructed in multi-layer coal seam goaves and its safety during operation. The main purpose of this paper was to evaluate the long-term stability of the Tianzimiao tunnel, which is constructed on a 
multi-layer coal seam by using long-term on-site monitoring. The main aim was threefold: (1) to investigate the specific geology and hydrogeology conditions of the Tianzimiao tunnel; (2) to present the on-site monitoring and other techniques and analysis methods used for rock subsidence and deformation; and (3) to analyze the monitoring data and evaluate the safety of the tunnel.

\section{Engineering Geological Conditions}

\subsection{Geography and Geology}

The Tianzimiao tunnel is located in the mountainous area near Tianzimiao, approximately $6.0 \mathrm{~km}$ to the northwest of Yangquan city in Shanxi province (Figure 1). Yangquan is in the eastern part of Shanxi province and is situated in the mountain basin on the west side of the middle section of the Taihang Mountains. It is surrounded by mountains with an altitude of 660 to $1272 \mathrm{~m}$. The average annual precipitation is $609.8 \mathrm{~mm}$, and it is mainly concentrated in July to September. The strata within the study area are generally flat, and they mainly strike toward NW and incline to SW, but there are certain changes in partial areas with a dip angle of 5 to $10^{\circ}$. The joint fractures in the study area are relatively developed, and they mainly strike toward the NE and NW and incline to the SE and SW with a large dip angle. The development of joints in rock masses is not only related to tectonic stress but also to the mining activities in the study area. According to the survey and mining data, in the study area, there are several normal faults that are oriented toward the NE and tend to the NW or SE, and the fault distance is moderate. Figure 1 shows the topography and geological conditions of the Tianaimiao tunnel. Table 1 shows the lithology of the strata.

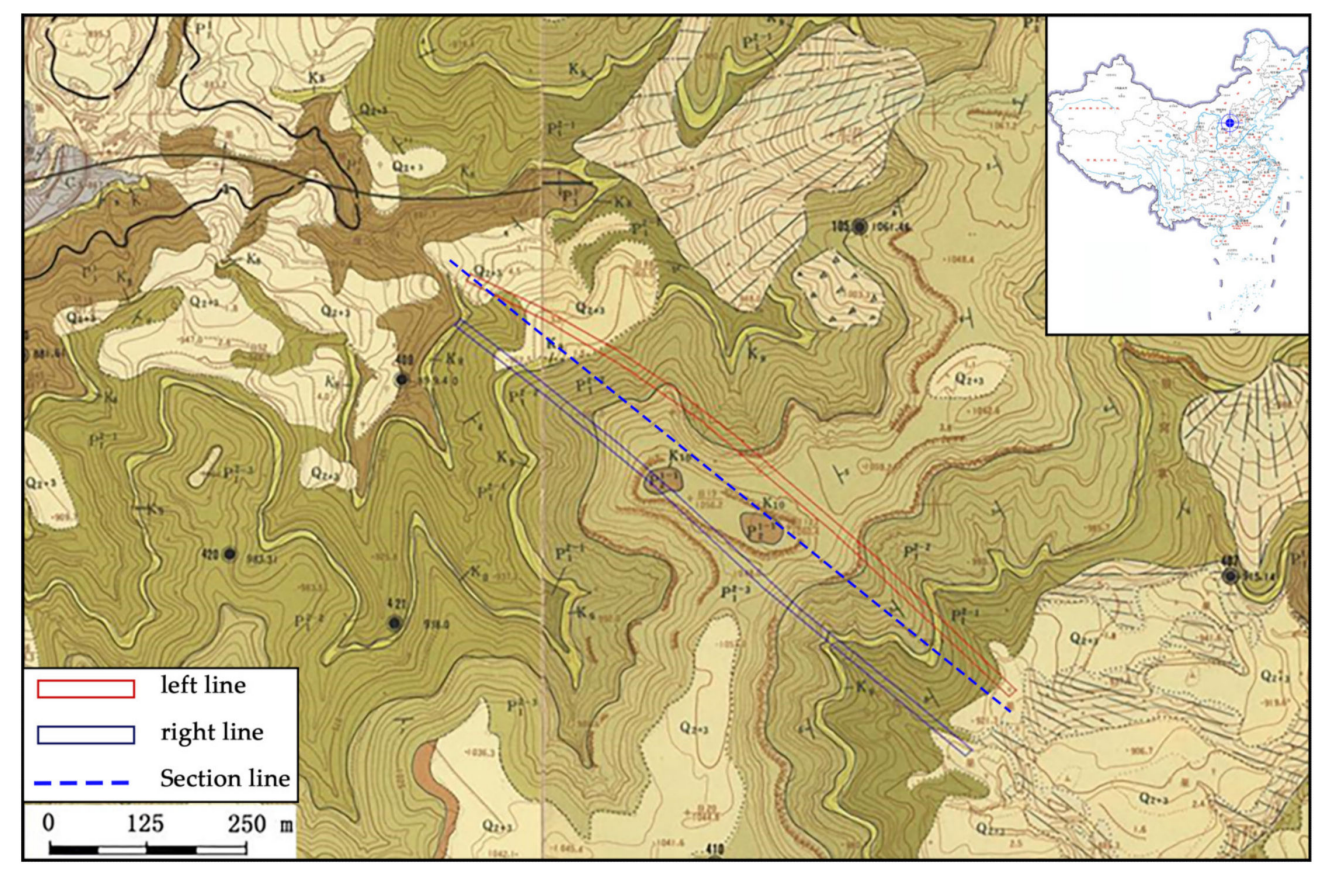

Figure 1. Location and geology of the Tianzimiao tunnel (the red one is left line and blue right). 
Table 1. Regional stratigraphy in Yangquan city.

\begin{tabular}{|c|c|c|c|c|}
\hline System & Formation & Symbol & Thickness (m) & Lithological Description \\
\hline Neogene & & Q & & $\begin{array}{l}\text { Loess, laterite, and loose alluvial materials } \\
\text { and deposits. }\end{array}$ \\
\hline \multirow{4}{*}{ Permian } & Shiqianfeng & $\mathrm{P}_{2 \mathrm{sh}}$ & 65.0 & $\begin{array}{l}\text { Bright red or mauve sandstone, sandy mudstone, } \\
\text { and mudstone. The bottom is K13, generally } \\
\text { coarse sandstone. }\end{array}$ \\
\hline & $\begin{array}{l}\text { Upper } \\
\text { Shihezi }\end{array}$ & $\mathrm{P}_{2 \mathrm{~s}}$ & 335.0 & $\begin{array}{l}\text { Reddish-brown sandy mudstone and } \\
\text { grayish-white sandstone, yellow, or yellow-green } \\
\text { mudstone and sandstone. }\end{array}$ \\
\hline & $\begin{array}{l}\text { Lower } \\
\text { Shihezi }\end{array}$ & $P_{1 x}$ & 117.0 & $\begin{array}{l}\text { Grayish-white or yellow-green coarse sandstone } \\
\text { and yellow mudstone. The top is K10 } \\
\text { peach-blossom color bauxite rock. }\end{array}$ \\
\hline & Shanxi & $P_{1 s}$ & 56.0 & $\begin{array}{l}\text { Gray-black terrigenous clastic rock and coal, } \\
\text { containing a total of } 6 \text { layers of coal which are, } \\
\text { respectively, numbered seam no. } 1,2, \ldots 6 \text { from } \\
\text { top to bottom. Among them, seam } 3 \text { is one of the } \\
\text { coal seams that can be mined in the whole region, } \\
\text { and the bottom K7 sandstone marker bed is } \\
\text { generally composed of grayish white coarse } \\
\text { sandstone of } \approx 6-10 \mathrm{~m} \text { thick. }\end{array}$ \\
\hline \multirow[t]{2}{*}{ Carboniferous } & Taiyuan & $C_{3 t}$ & 137.0 & $\begin{array}{l}\text { Grayish-black or gray sandstone, sandy } \\
\text { mudstone, limestone, and coal, containing a total } \\
\text { of six layers of coal which are, respectively, } \\
\text { numbered seam no. } 8 \text { to } 15 \text { from top to bottom. } \\
\text { Among them, seams } 8,12,13 \text {, and } 15 \text { can be } \\
\text { mined, and the bottom } \mathrm{K} 1 \text { sandstone is generally } \\
\text { composed of grayish white feldspar quartz } \\
\text { sandstone of } \approx 5-15 \text { m thick. }\end{array}$ \\
\hline & Benxi & $\mathrm{C}_{2 \mathrm{~b}}$ & 55.0 & $\begin{array}{l}\text { Black mudstone, gray bauxite (mineral) rock, } \\
\text { dark gray mudstone limestone, and thin coal } \\
\text { seams. The bottom is "Shanxi-type iron ore" or } \\
\text { "Yangquan-type pyrite". }\end{array}$ \\
\hline Ordovician & Majiagou & $\mathrm{O}_{2 \mathrm{~m}}$ & $600-800$ & Limestone \\
\hline
\end{tabular}

\subsection{Engineering Geology}

The bedrock of the study area is bare, and there are loose deposits only in the foothills. The bedrock is a rock combination of the Permian to Carboniferous system. There are significant lithology changes in the study area, and the rock composition has a layered distribution in terms of mechanical strength. Therefore, according to the characteristics of the rock combination in the study area, the rock mass can be divided into five engineering geological types (ET), namely, sandstone, mudstone, limestone, sandstone-mudstone inter-bedded type, and caving ETs (deposited rock mass in goaf).

Based on the principle of engineering geology classification mentioned above and the results of the engineering geological surveying as well as the mapping of the tunnel mountain, the rock types within the depth range of the seam no. 15 from the top of the tunnel to the underground were classified based on their ETs (Figure 2), and a total of 19 ETs were identified from bottom to top. 


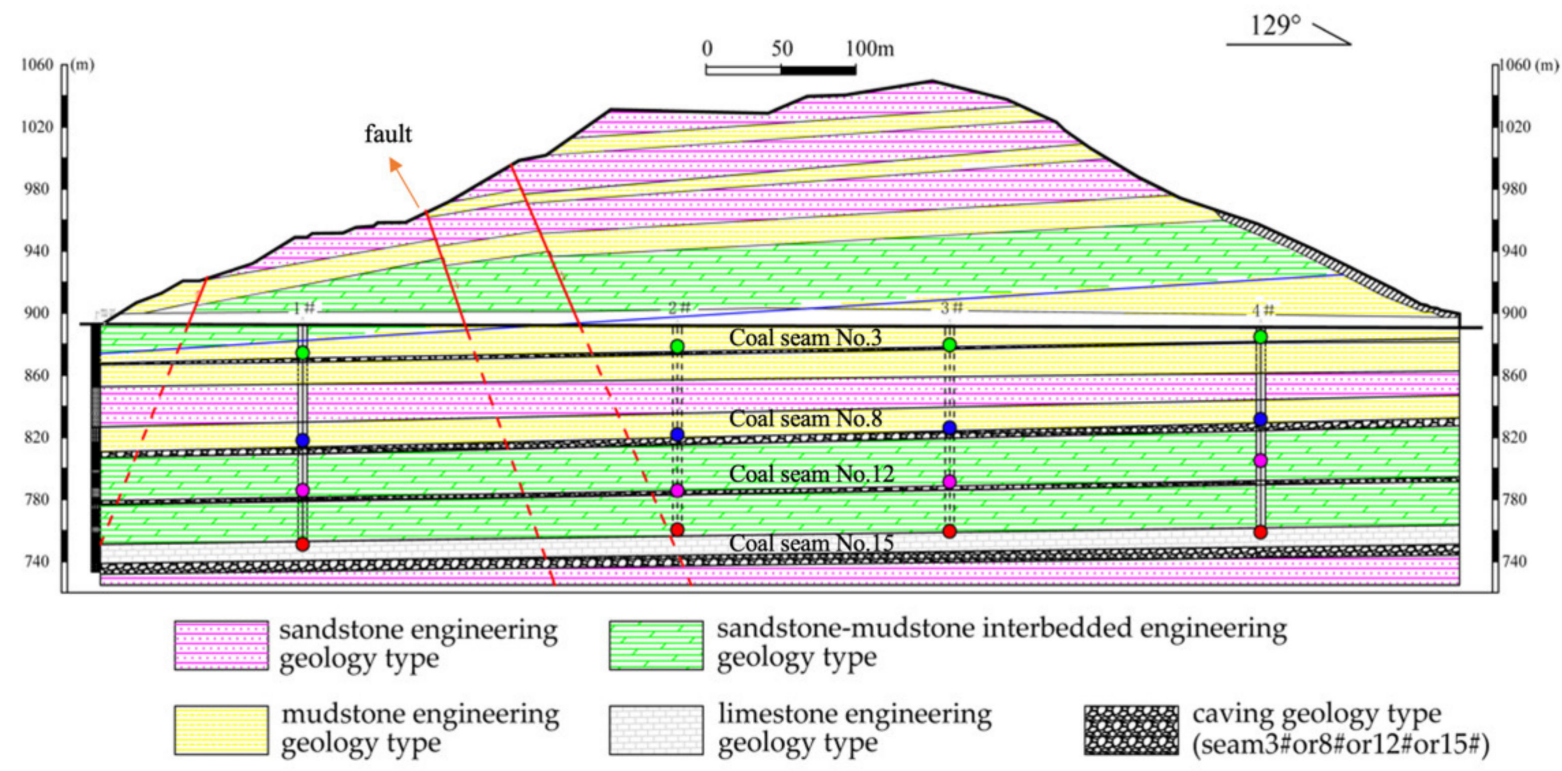

Figure 2. Engineering geological types of the Tianzimiao tunnel.

In the engineering geological mapping of the mountain, the development of mountain cracks was specially investigated and measured, which was mainly carried out on the top of the mountain, and the distribution and strike rose diagram of cracks were plotted (Figure 3).

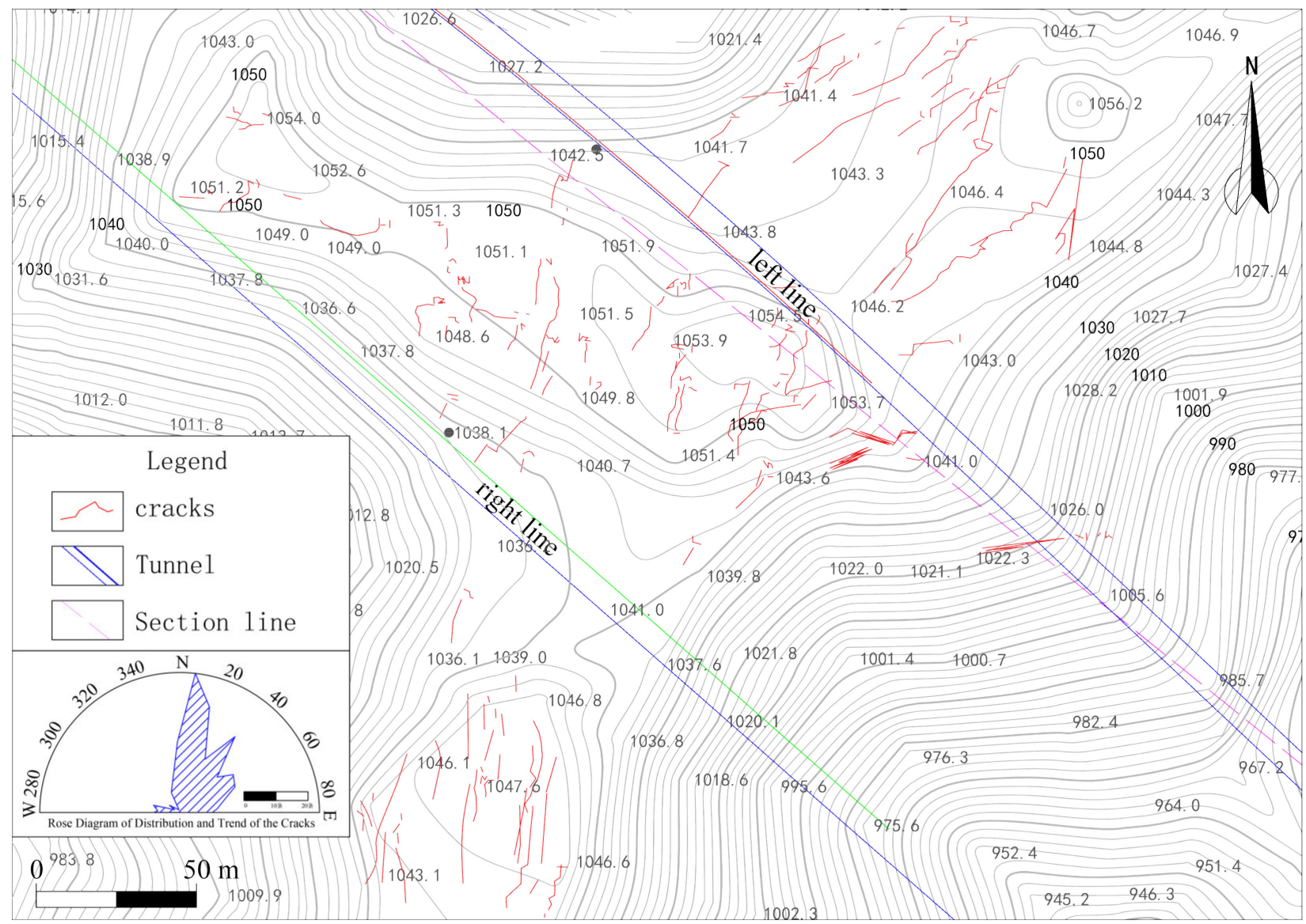

Figure 3. Distribution and strike rose diagram of cracks in the mountain of the Tianzimiao tunnel. 
The main cause of the mountain cracks is underground coal mining. The strike of cracks is consistent with the direction of the coal mining panel, on the one hand, and on the other hand, the orientation of slope and the early developed joints have an obvious inducing effect on the formation of cracks.

\subsection{Characterization of Goaves}

The Tianzimiao tunnel site is a goaf site, and there are four layers of exploited and recoverable coal seams in the lower part: mainly including seam no. 3, 8, 12, and 15, among which the goaves of seam no. 3, 12, and 15 are located within the boundary of the Yangquan Coal Mining Group. The seam no. 8 coal goaf belongs to the mining area boundary of the Yangquan Coal Mining Group and the Hanhegou coal mining area. In order to ensure the safety of the Tianzimiao tunnel, the goaves of seam no. 3 and 8 have been grouted in the tunnel construction process.

The distribution of the main recoverable coal seams in the study area: seam no. 3 is $2.0 \mathrm{~m}$ thick, and its depth from the tunnel floor is 21.5 to $26.4 \mathrm{~m}$; seam no. 8 is 0 to $1.5 \mathrm{~m}$ thick (unsteadily distributed), and its distance from the tunnel floor is 77.9 to $84.5 \mathrm{~m}$; seam no. 12 is approximately $1.5 \mathrm{~ms}$ thick, and its depth from tunnel floor is 110.8 to $116.1 \mathrm{~m}$; seam no. 15 is approximately $6.0 \mathrm{~m}$ thick, and its depth from the tunnel floor is around $165 \mathrm{~m}$.

According to the available dates of the Yangquan Coal Mining Group, seam no. 3 in the study area was mined in 1959 to 1960, seam no. 12 was mined in 1969 to 1981, seam no. 15 was mined in 1982 to 1996, and the individual panels of seam no. 15 were mined in 2001.

The drilling preliminary ascertained the depth, thickness, and compactness of the goaves in the study area, and it verified the mining conditions of seam no. 8 that were not reflected by the mining data; thus, important results were achieved.

During the drilling process, it was found that there was water leakage in the goaf of seam no. 3, and there was a small amount of water leakage and borehole collapse in the goaf of seam no. 12. In addition, there were many instances of drilling bit burying in the drilling process. The above-mentioned phenomenon suggests that the integrity of the rock mass was poor, and the rock mass in the collapse zone of the deep goaf was relatively broken due to the impact of rock mass collapse above the goaves.

In order to further test the integrity of the rock strata and the collapse and compaction of the overlying rocks in the goaf, water injection tests were carried out in Z1, Z2, Z3, Z6, 1-4, and 4-4 drillings boreholes. The water injection volume, the change in the groundwater level, and the test time were recorded, and the water injection curves of each borehole were obtained.

The results of the water injection test show that: (1) the goaf of seam no. 3 has been grouted, the water flow velocity is very low, and there are slight differences in different sections; (2) the goaves of seam no. 12 and 15 have been preliminary compacted, and there are still some gaps in compaction, but the water flow rate of the water injection test is also very low with a maximum value of $0.065 \mathrm{~m}^{3} / \mathrm{min}$, indicating that the porosity is not large [33].

The scope of the goaf exposed by borehole drilling is relatively limited, and a combination of various exploration methods was used to facilitate a more comprehensive understanding of the distribution of shallow goaves (for seam no. 3 and 8) under the tunnel site and the treatment effect of goaves. Additionally, this also provides a scientific and rational basis for whether or not follow-up treatment will be needed.

Due to the fact the shallow goaves were mined at a very early stage and there are small coal mining pits, the distribution of shallow goaves in the study area could not be accurately ascertained by the method of investigation and interview. Therefore, a seismic exploration was carried out in the section of K12 + 853 to K13 + 400 of the left line and RK12 + 902 to RK13 + 400 of the right line of the tunnel, so as to determine the mining situation and distribution of seam no. 3 and 8 . 
Based on the comprehensive analysis of the seismic time-distance profile of each survey line, the distribution maps of the goaves of seam no. 3 and 8 within the range of the left and right lines in the tunnel were obtained (Figure 4).

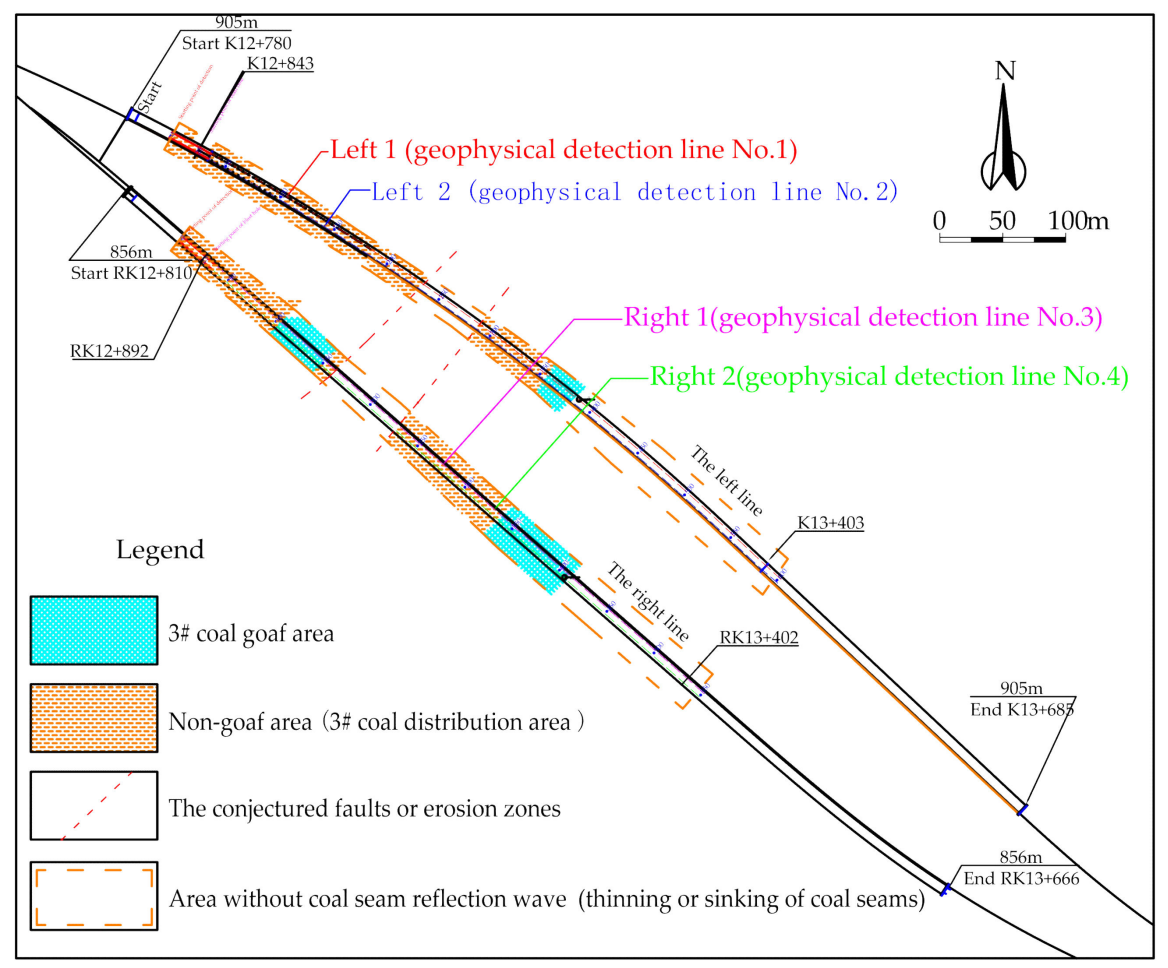

(a) Seam no. 3.

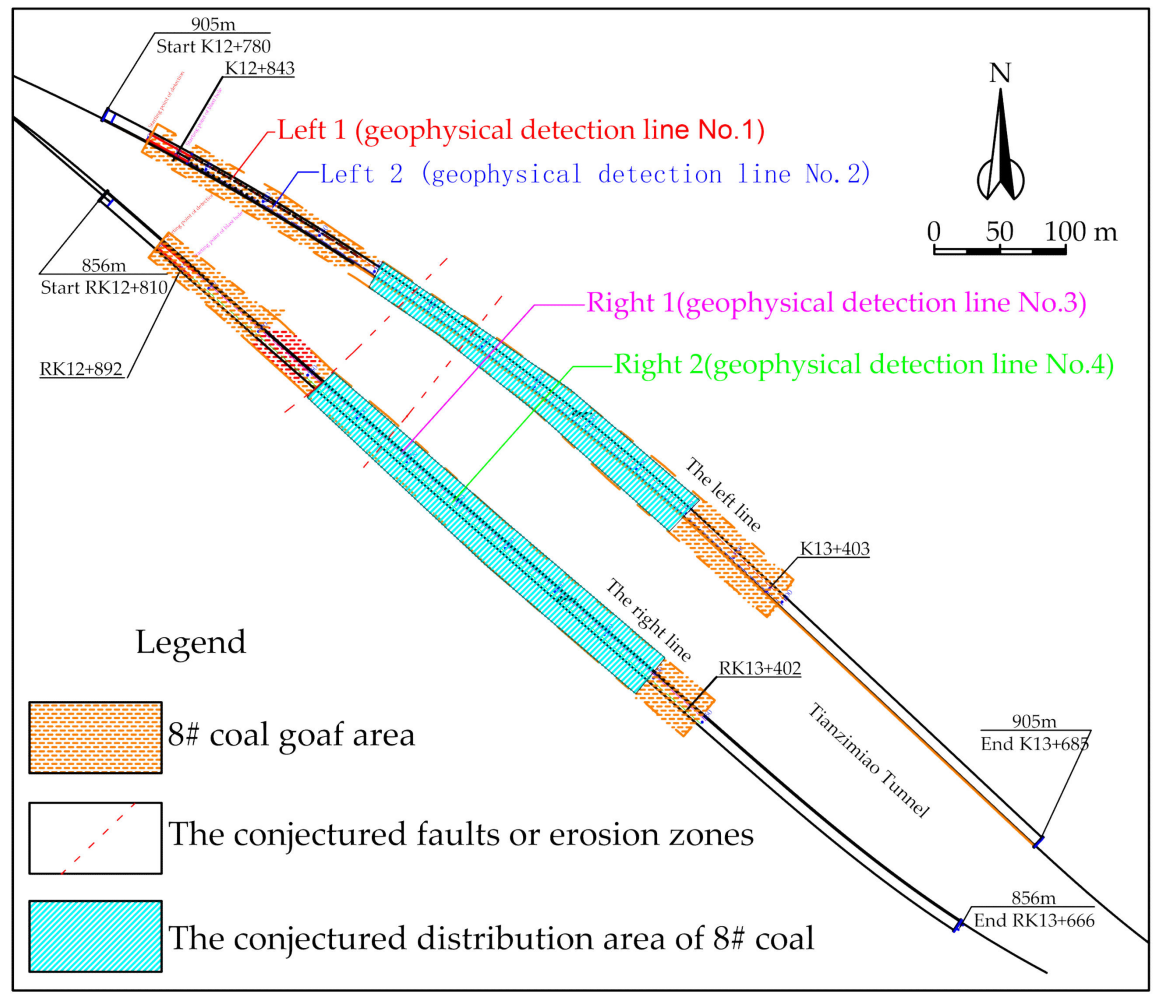

(b) Seam no. 8 .

Figure 4. Distribution of the goaves beneath the Tianzimiao tunnel. 
By synthesizing the drilling, water injection test, and seismic exploration, the following are believed: (1) the shallow part of section RK12 + 970 to RK13 + 24 of the right side of the tunnel is the goaf of seam no. 3, but it has been grouted; (2) the reflected waves at section K13 + 172-217 of the left line and section RK13 + 202-274 of the right line of the tunnel are relatively disordered, but the drilling and water injection test showed no signs of goaves in seam no. 3 , which is presumed to be caused by the interference to seismic reflection waves caused by adjacent roadways; (3) the disturbed stratum in the shallow part of section K13 + 52-105 on the left line and RK13 + 29-96 on the right line is due to the erosion zone of seam no. 3; (4) 1-3 and 4-4 borehole drilling exposes the goaf of seam 8 , so it is predicted that there has been coal mining in seam no. 3 at the northwest and southeast ends of the tunnel, while seam no. 8 in the middle of the tunnel is normally distributed and thinned; (5) seam no. 12 and 15 both were mined out within the range of the study area [33].

\section{Methods}

The monitoring work for the tunnel started immediately after the completion of the tunnel construction, which mainly included the following: subsidence and deformation of the underground goaves; tangential stress of the secondary lining inner arch; the axial and tangential stress of the surrounding rock; deformation of the tunnel and the mountain.

\subsection{Settlement and Deformation in Deep Goaf}

Through the deep bedrock subsurface embedded in the underground goaf (Figure 5), the subsidence and deformation of the four-layer goaves (buried in the roofs of seam no. 3, 8,12 , and 15 , respectively) beneath the tunnel were monitored. If the deformation of the deep mined out area is limited, the tunnel would be safe. If there is any large deformation, it will be imperative to make a prediction of its impact on the tunnel safety as the deformation of deep goaf will occur before the deformation of the tunnel.

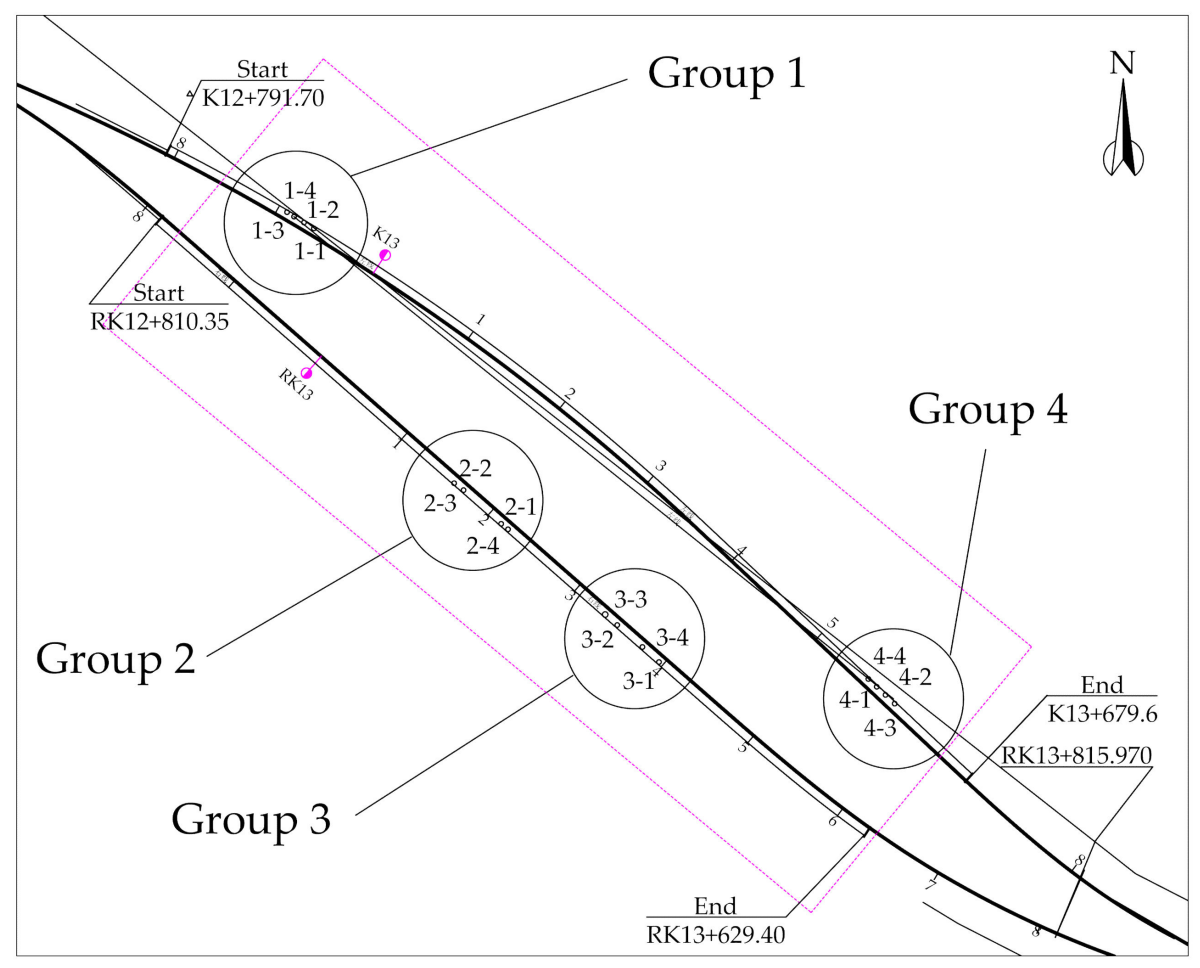

(a)

Figure 5. Cont. 


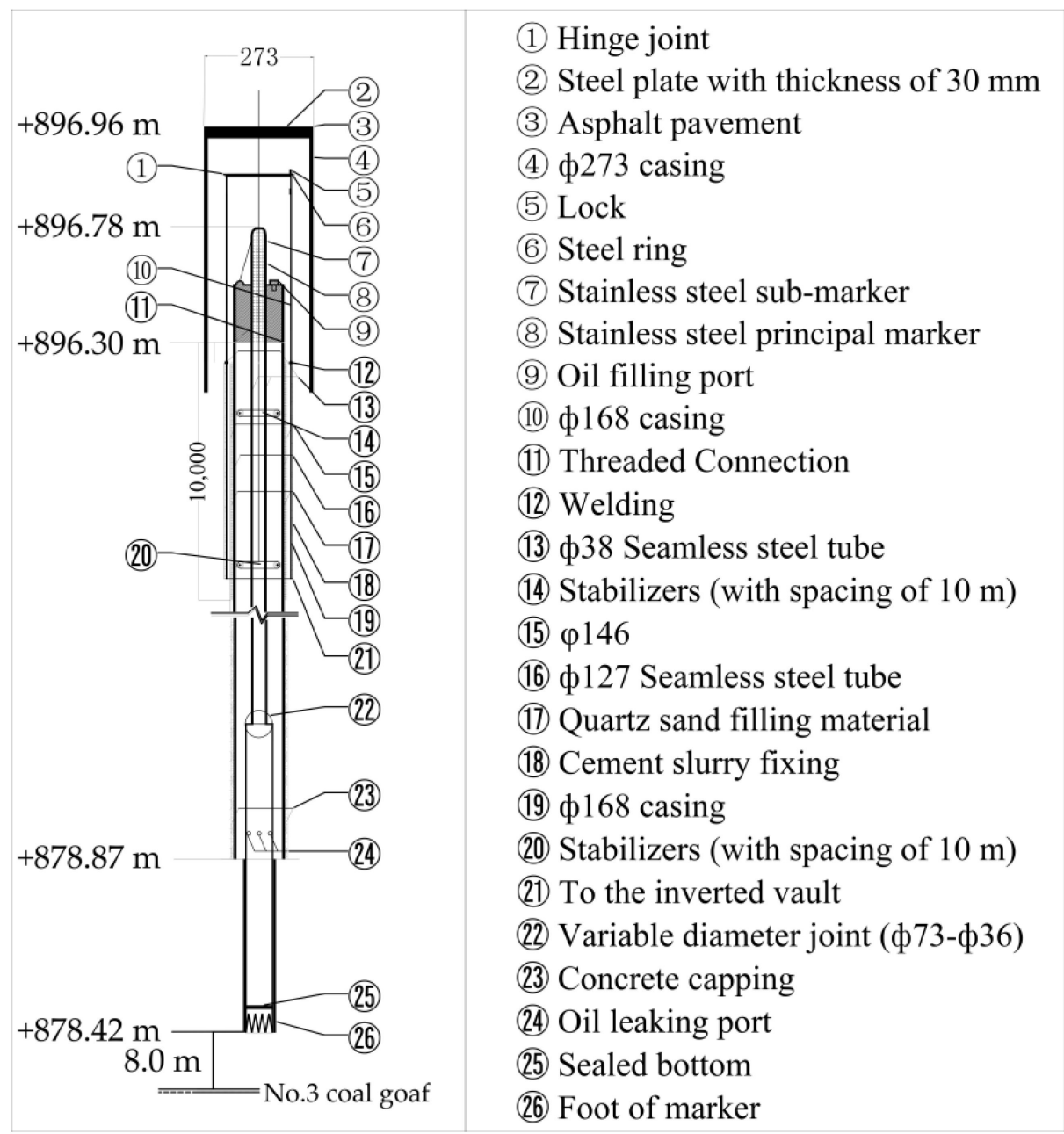

(b)

Figure 5. Bedrock marker installation diagram: (a) layout of boreholes; (b) structure of marker.

Deep monitoring markers, which are used for the monitoring of the whole moving belt deformation, were buried in the caving zone above the goaf of each coal seam (seam no. $3,8,12$, and 15) by drilling, and by monitoring the deformation (second-class leveling) of the upper headers; the deformation of the caving zone in the goaf was measured. Figure 5a shows the layout of the boreholes for installing the bedrock markers.

\subsection{Stress of Surrounding Rock and Internal Arch}

In order to predict the safety of the tunnel, the stress sensors and rebar stress gauge (Figure 6) were embedded in fixed position of the surrounding rock and secondary lining, the tangential stress of the secondary inner lining, and the axial stress. The tangential stress of the surrounding rock was monitored, and the deformation of the surrounding rock and the secondary lining was measured according to the sponsors. Figure 6 shows the construction layout of the stress sensors and rebars stress gauges for the surrounding rocks and linings of the tunnel, and the structure of the rebar stress gauge. According to the type of surrounding rock of the tunnel and its supporting conditions, five measuring sections were installed on the left and right lines. 


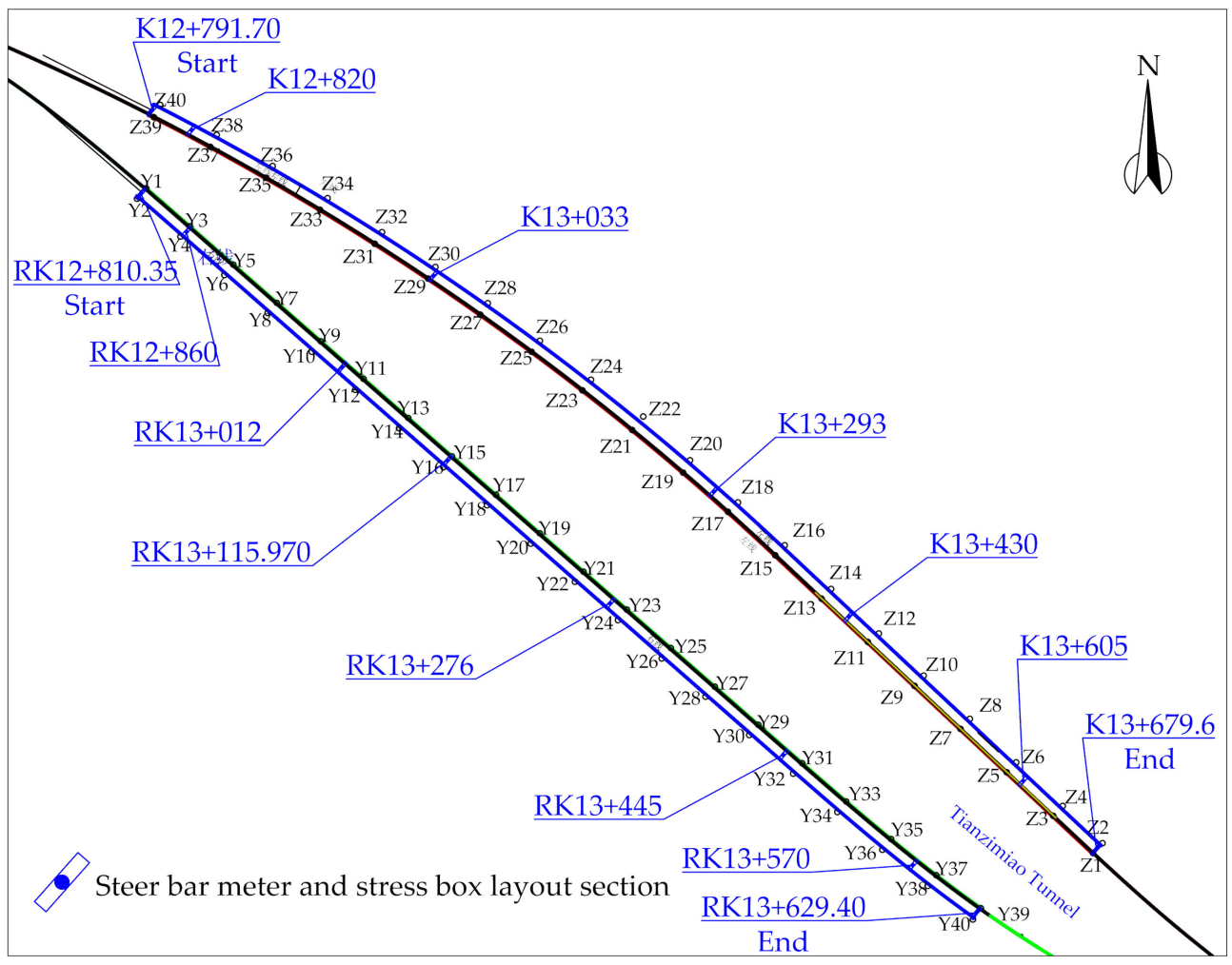

(a) Plane layout of stress sensors and rebar stress gauge.

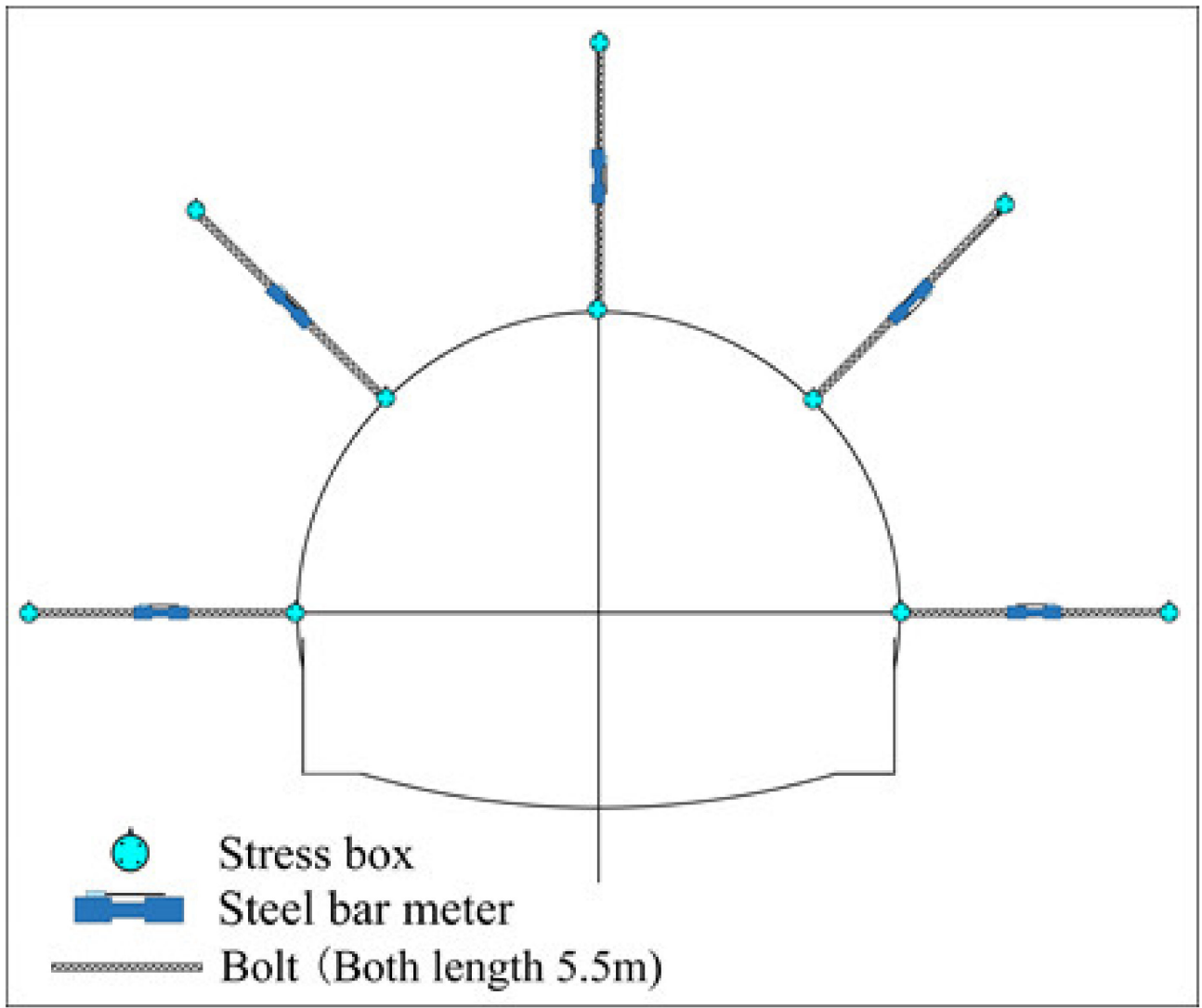

(b) Sectional layout stress sensors and rebar stress gauge. 


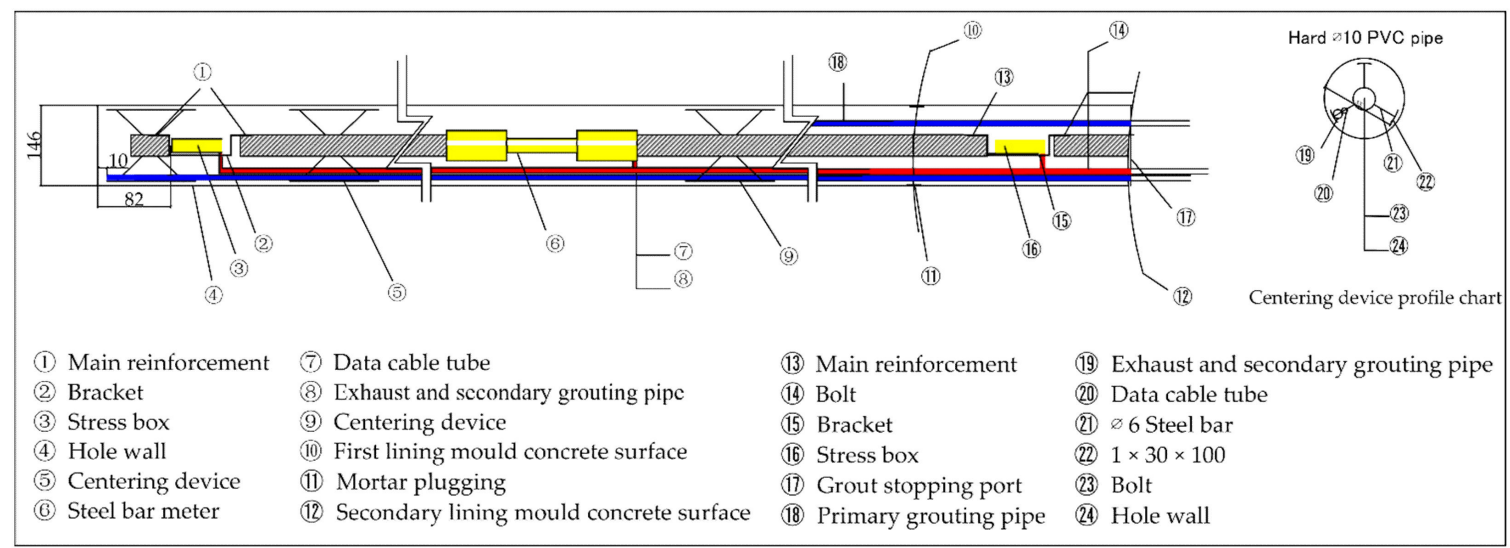

(c) Structure of rebar stress gauge.

Figure 6. Layout of stress sensors and rebar stress gauge in tunnel.

\subsection{Deformation of the Tunnel and Mountain}

Subsidence markers were embedded on both walls of the tunnel. When the deformation exceeded a certain value (the inclination exceeds to $1 \%$ [34]), the forecast would be made in advance. The mountain above the tunnel was also embedded with a subsidence marker to form a monitoring network. Figure 7 shows the layout of the mountain deformation monitoring markers at the end of the tunnel. Settlement markers were arranged every $40 \mathrm{~m}$ around the two sidewalls of the left and right tunnels, and a total of 80 observation markers were arranged for the two tunnels. Twenty mountain surface settlement observation points (numbers S1-S20) were arranged on the mountain above the east and west portals of the tunnel, and the reference points were set up at appropriate positions outside the portals.

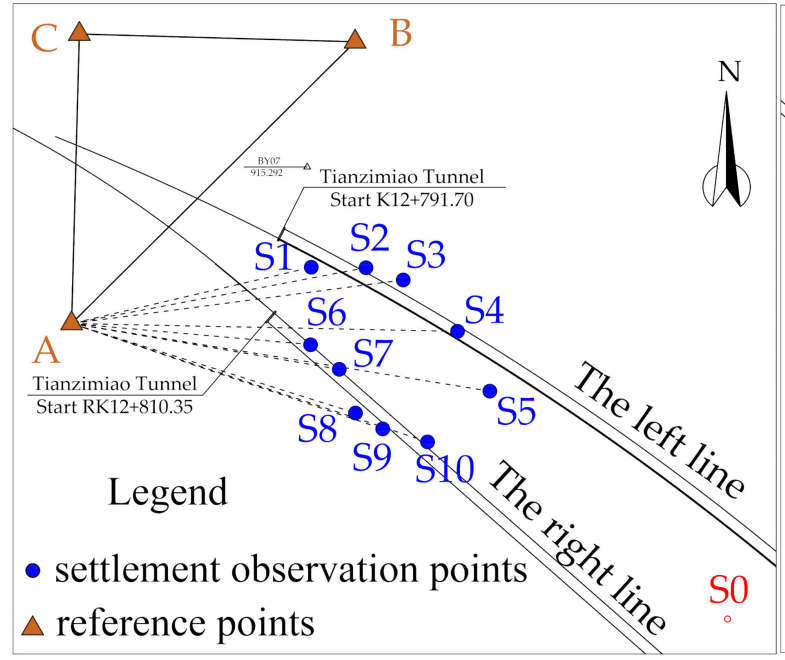

(a) Northwest portal.

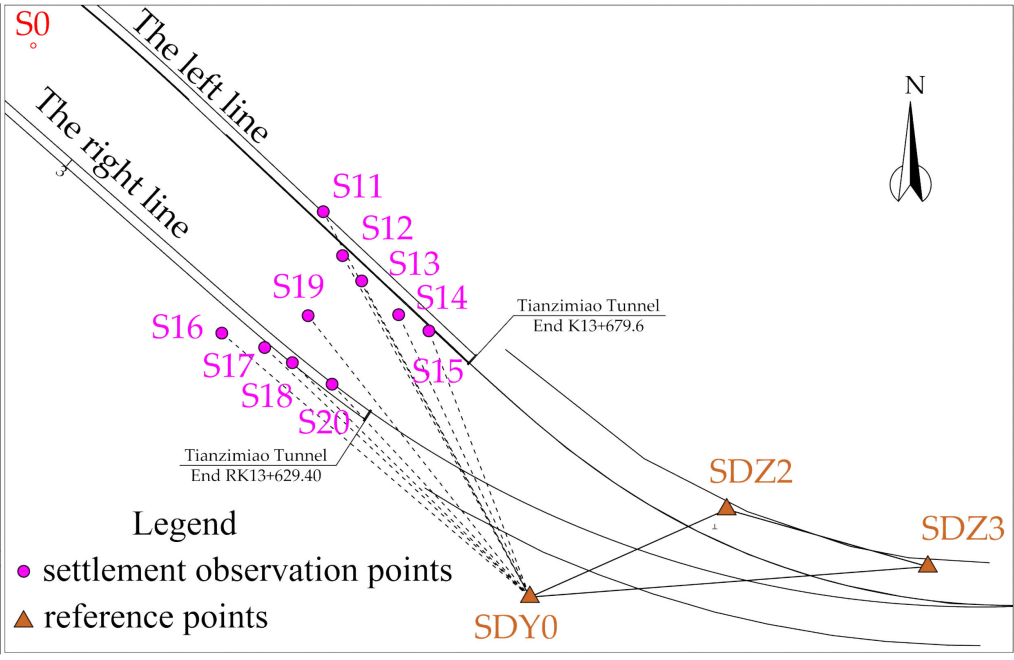

(b) Southeastern portal.

Figure 7. Layout of mountain surface settlement observation points.

The monitoring period of this project was eight years, during which the tunnel wall and mountain settlement and the stress of the tunnel surrounding rock and the secondary lining were monitored 22 times. The deep monitoring markers in the goaf were monitored 17 times. 


\section{Results and Analysis}

\subsection{Settlement and Deformation of Bedrock}

According to the observational data, as of 9 March 2015, the bedrock marker subsidence was relatively uniform compared with the datum point subsidence, and the subsidence was generally smaller in the southeast and larger in the northwest (Figure 8).

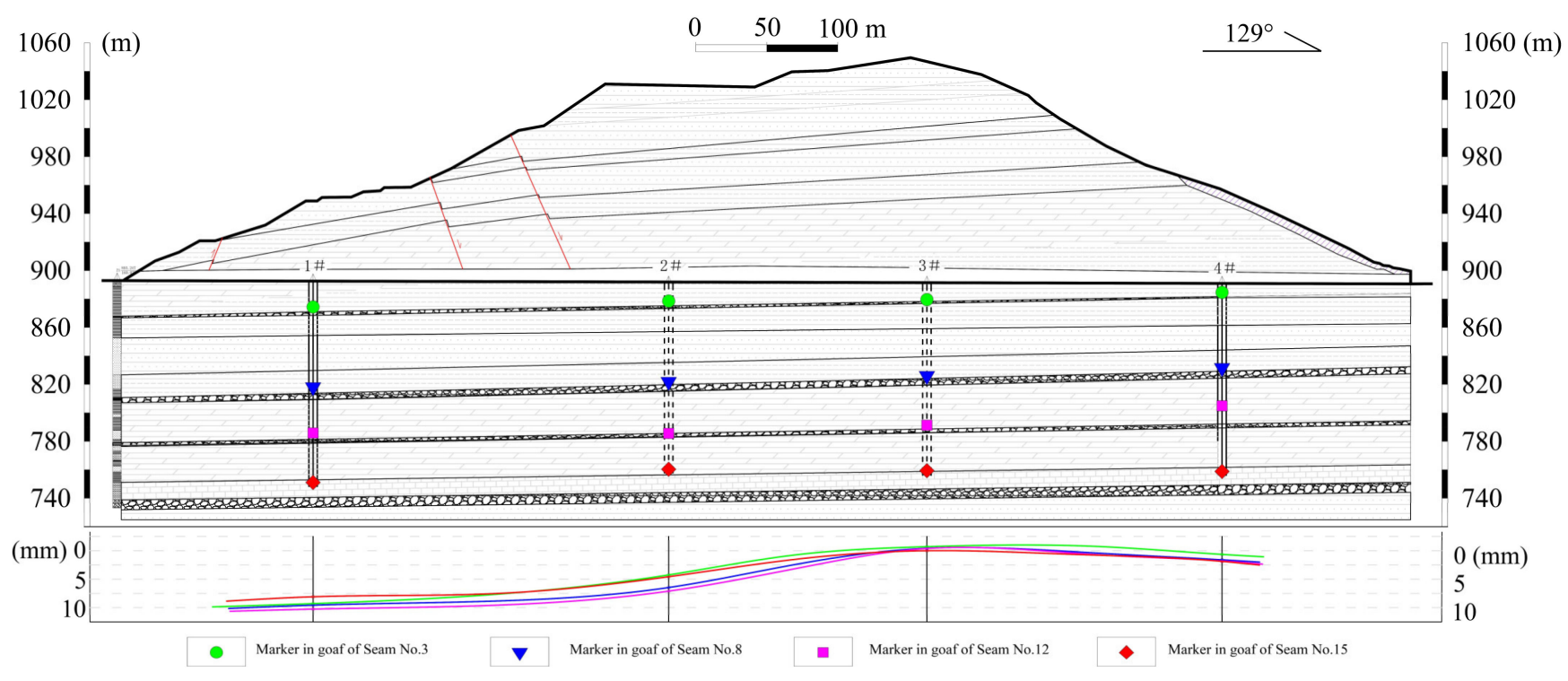

Figure 8. Settlement of bedrock markers in the goaf (maximum slope: $0.05 \%$ ).

The bedrock marker with the largest amount of subsidence in the northwest is the bedrock marker 1-31 in the roof of seam no. 12, with a cumulative amount of $16.19 \mathrm{~mm}$ and the tunnel surface maximum inclination of $0.05 \%$. As shown in the settlement curve in Figure 9, although there are differences in the settlement of the goaves in different sections, the trends of settlement of the bedrock markers at different depths of the same section are basically the same. The data listed in Table 2 show the subsidence speed variation in the goaf during monitoring, of which the first stage is the construction period (from October 2007 to July 2008), the second stage is the trial operation period (from August 2008 to April 2009), and the third stage is the operation period (from May 2009 to March 2015).

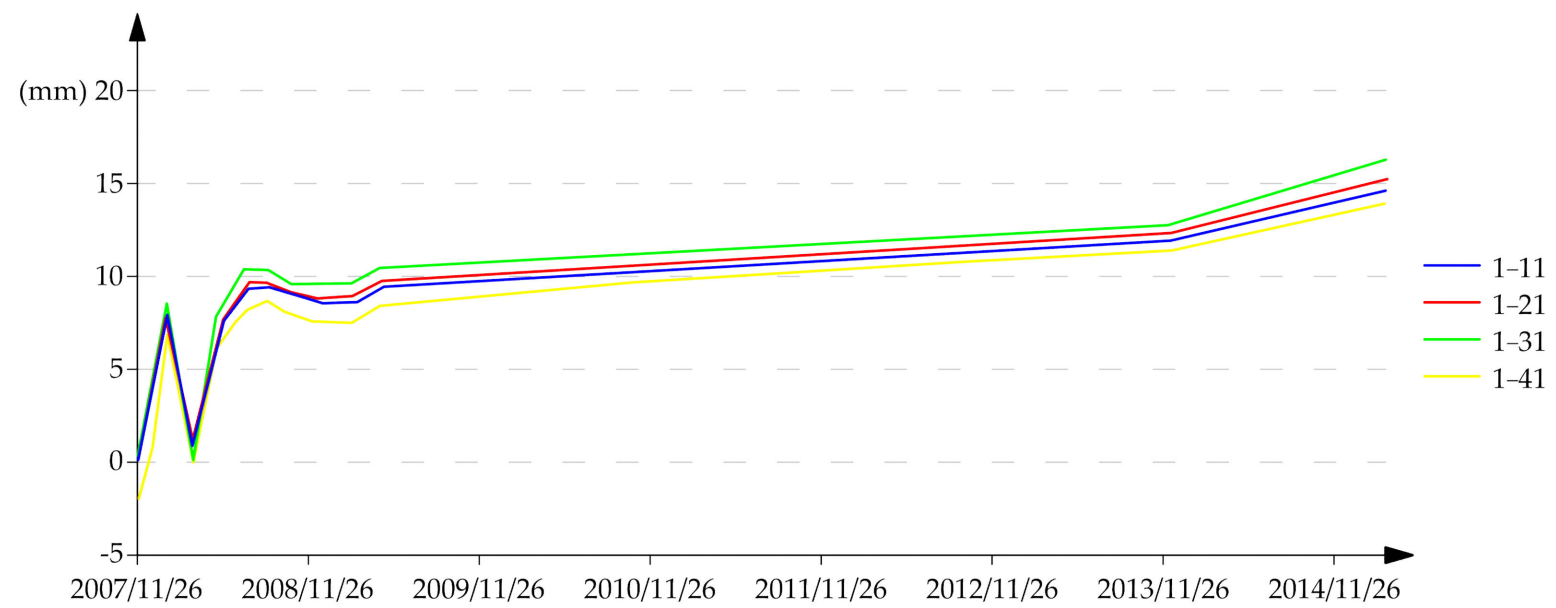

(a) the 1st group

Figure 9. Cont. 


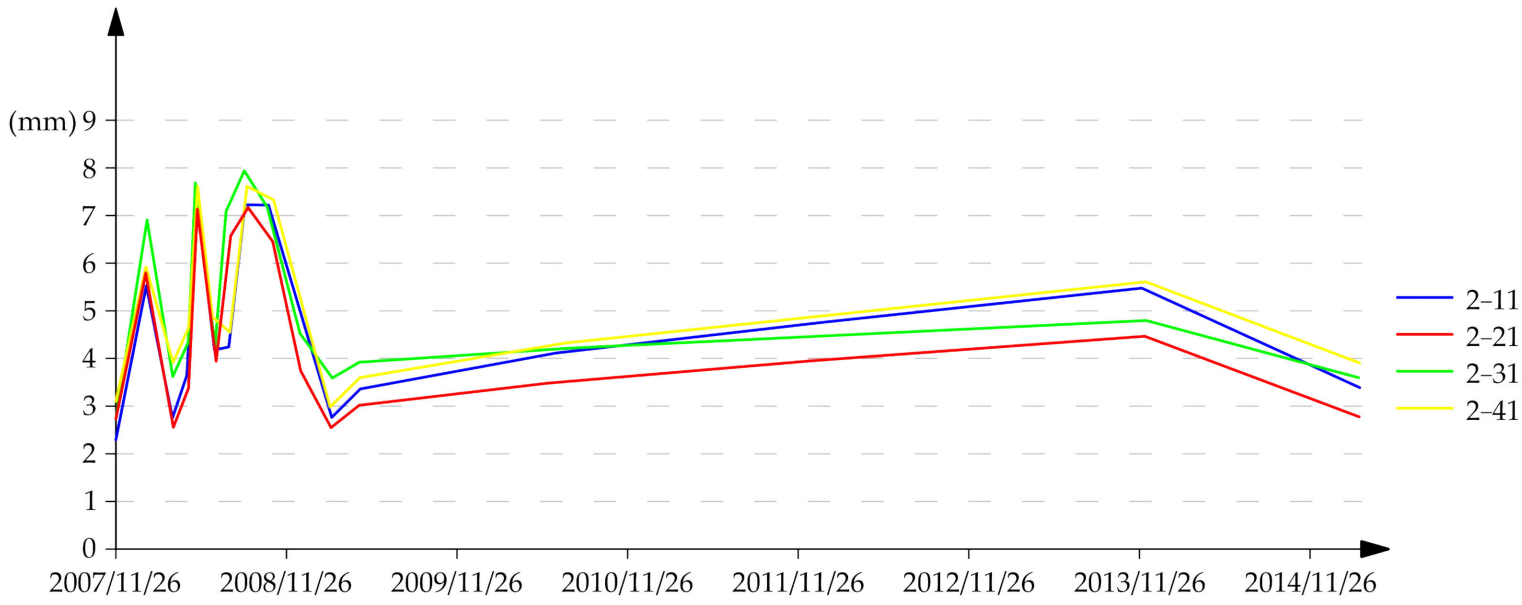

(b) the 2nd group

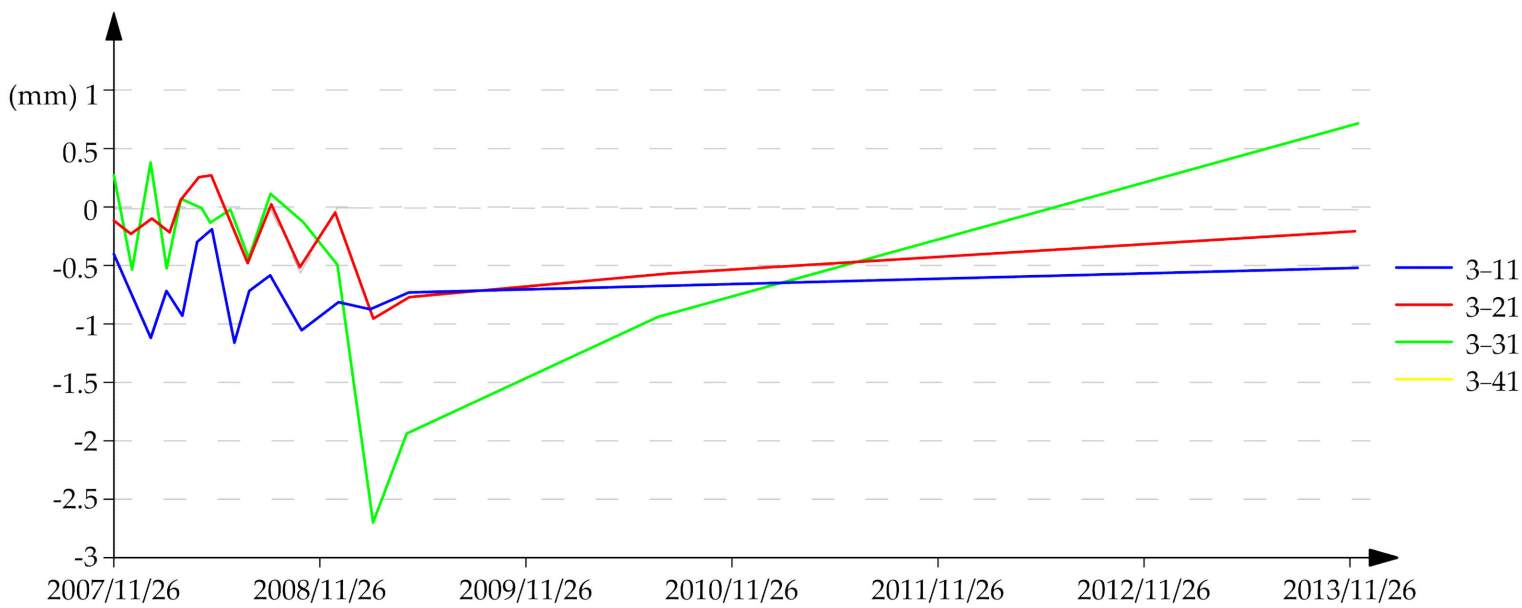

(c) the 3rd group

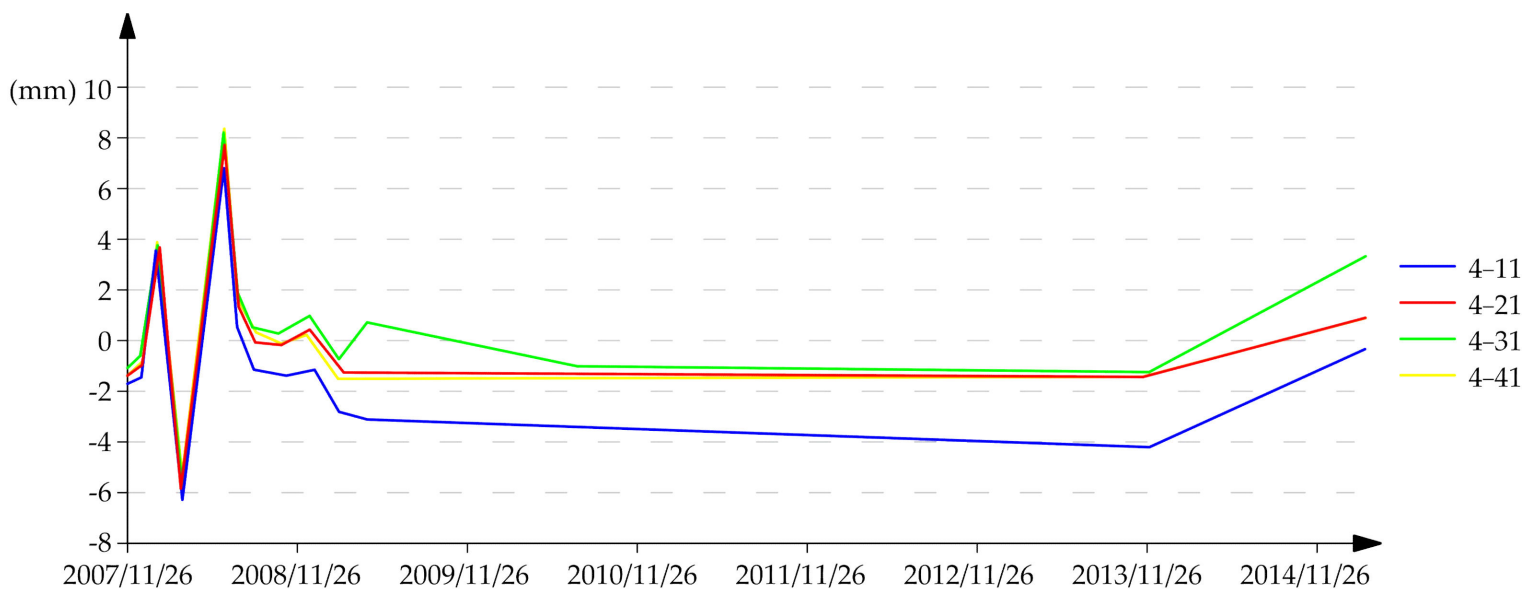

(d) the 4th group

Figure 9. Accumulative settlement for bedrock markers in the goaves. 
Table 2. Subsidence speed variation for bedrock markers in the goaf.

\begin{tabular}{|c|c|c|c|c|}
\hline \multirow{2}{*}{ Bedrock Group } & \multirow{2}{*}{$\begin{array}{l}\text { No. of Bedrock } \\
\text { Marker }\end{array}$} & \multicolumn{3}{|c|}{ Subsidence Speed Variation (mm/month) } \\
\hline & & The First Stage & The Second Stage & The Third Stage \\
\hline \multirow{4}{*}{$\begin{array}{c}\text { The First Group } \\
\text { Bedrock }\end{array}$} & $1-11$ & 0.931 & -0.009 & 0.536 \\
\hline & $1-21$ & 0.957 & 0.004 & 0.558 \\
\hline & $1-31$ & 1.026 & 0.003 & 0.590 \\
\hline & $1-41$ & 0.809 & 0.023 & 0.560 \\
\hline \multirow{4}{*}{$\begin{array}{c}\text { The Second Group } \\
\text { Bedrock }\end{array}$} & $2-11$ & 0.425 & -0.099 & 0.002 \\
\hline & $2-21$ & 0.647 & -0.387 & -0.021 \\
\hline & $2-31$ & 0.710 & -0.359 & -0.032 \\
\hline & $2-41$ & 0.457 & -0.111 & 0.031 \\
\hline \multirow{4}{*}{$\begin{array}{c}\text { The Third Group } \\
\text { Bedrock }\end{array}$} & $3-11$ & -0.071 & -0.002 & 0.028 \\
\hline & $3-21$ & -0.044 & -0.038 & 0.074 \\
\hline & $3-31$ & -0.039 & -0.170 & 0.331 \\
\hline & $3-41$ & 0 & 0 & 0 \\
\hline \multirow{4}{*}{$\begin{array}{c}\text { The Fourth Group } \\
\text { Bedrock }\end{array}$} & $4-11$ & 0.065 & -0.404 & 0.279 \\
\hline & $4-21$ & 0.160 & -0.310 & -0.013 \\
\hline & $4-31$ & 0.180 & -0.114 & 0.261 \\
\hline & $4-41$ & 0.187 & -0.369 & 0.241 \\
\hline
\end{tabular}

As shown in the observed data, there are fluctuations in the observed fractional subsidence, and sometimes, its value might even be negative. As a result, the cumulative subsidence curve and the staged subsidence speed curve both show abnormal fluctuations. There is an obvious consistency in the fluctuations of the observed data; that is, each observed value is either generally high or low, or generally positive or negative; the observed fractional subsidence value is already very small, and the value fluctuates around \pm 0 , with the absolute value generally less than $4 \mathrm{~mm}$.

Through the analysis of the observed data and the outcome drawings, the settlement in the goaf of the study area has become stable, and the settlement is very small; the maximum inclination of the tunnel surface is $0.05 \%$, so the settlement is uniform on the whole.

\subsection{Subsidence of Tunnel Side Wall}

The subsidence markers at the side walls of both tunnels have all subsided; the accumulative settlement increased from the southeast to the northwest (Figure 10), which is consistent with the subsidence trend of the bedrock marker in the goaf, indicating that the settlement of the tunnel side wall is also caused by the subsidence of the goaf. Figure 10a shows the curve of the subsidence of the left line side wall of the tunnel, and Figure 10c shows the curve of the right line. The horizontal axis is the tunnel chainage.

As can be seen by comparing the numerical calculations results that Ding forecasted [34] (the red curve in Figure 11) with the results of the settlement monitoring at the present stage (the black curve in Figure 11), the measured ground subsidence is consistent with the estimated total residual settlement of the surface (Figure 11). At the present stage, the maximum settlement of the side wall is $23.11 \mathrm{~mm}$, which is smaller than the result of the prediction. The slope of the ground is almost negligible (the slope of the left and right sidewalls is 0.05 to $0.06 \%$ ). Therefore, the tunnel is safe at the current operation stage in the serviceability condition. 


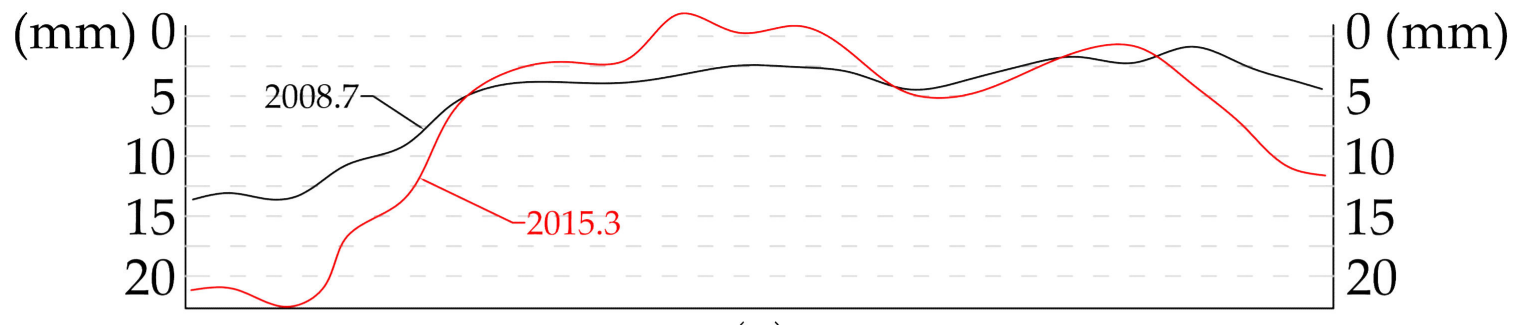

(a)

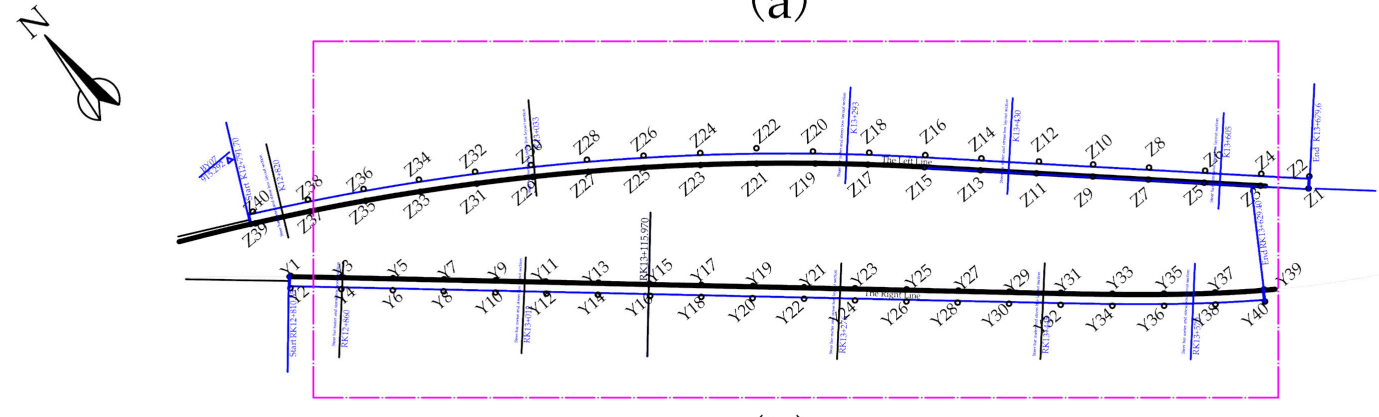

(b)

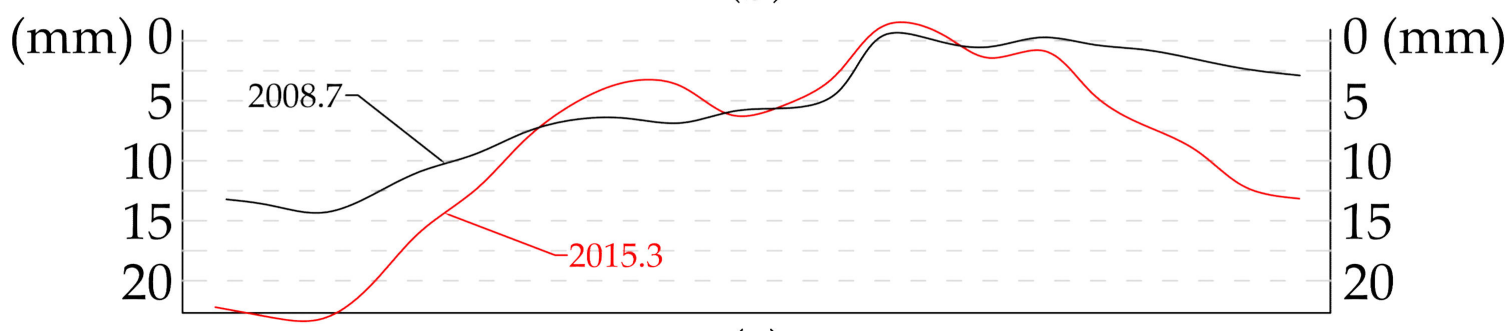

(c)

Figure 10. Subsidence of the side wall of the tunnel. (a) Subsidence of the left line side wall. (b) Layout of subsidence markers at the side walls. (c) Subsidence of the right line side wall.

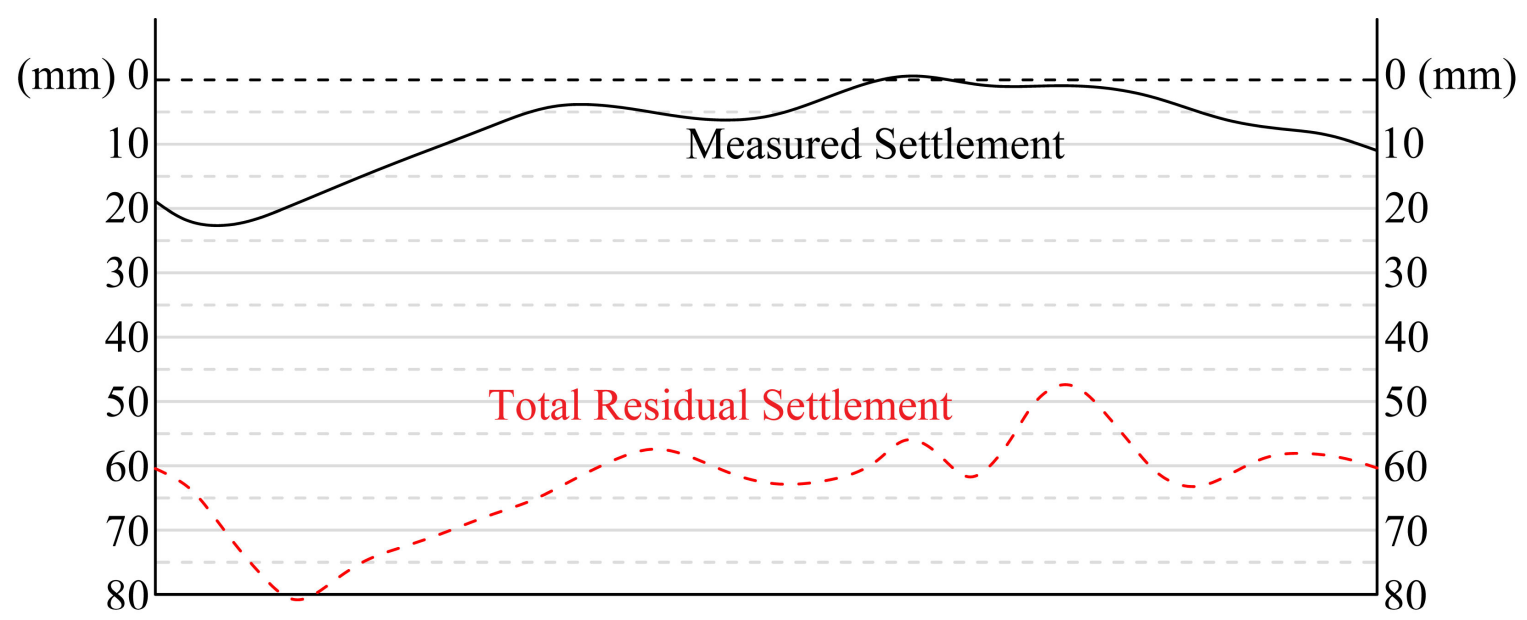

Figure 11. Contrast curve of measured settlement and total residual settlement of the tunnel sidewalls.

\subsection{Rebar Stresses}

The observation results of the rebar stresses gauges and stress sensors of the tunnel surrounding rock and masonry lining are shown in Figure 12. Generally, if the data of rebar stresses were suddenly changed, the safety of the tunnel would be affected. 


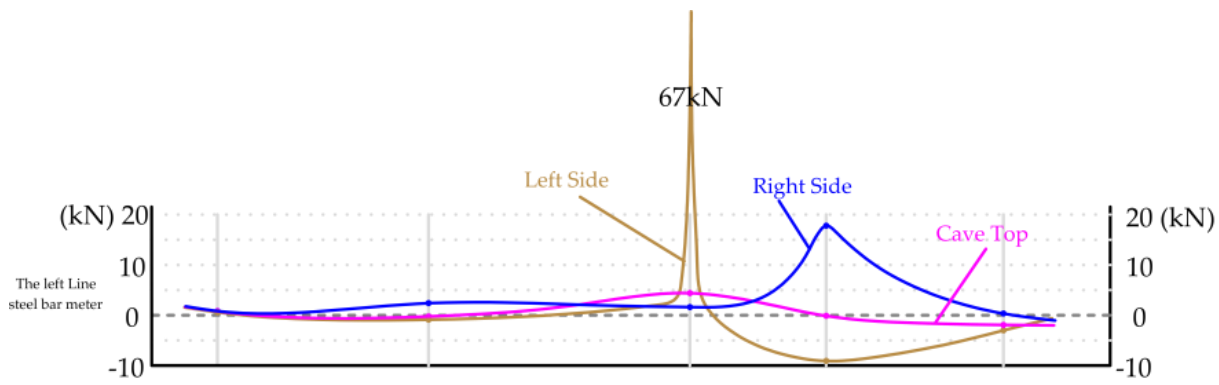

(a)

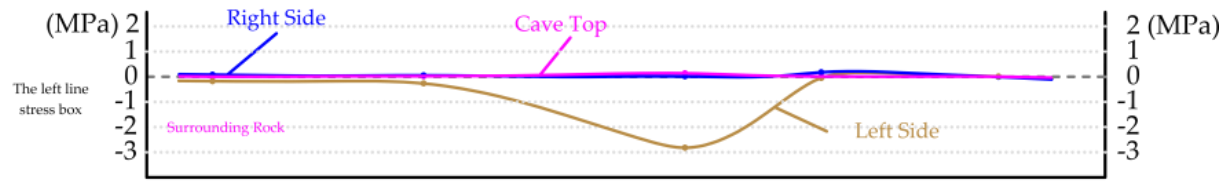

(b)

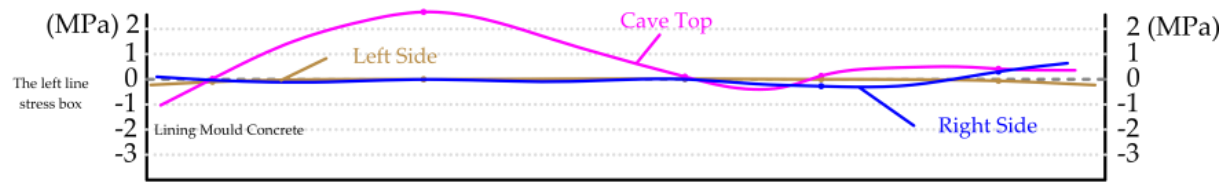

(c)

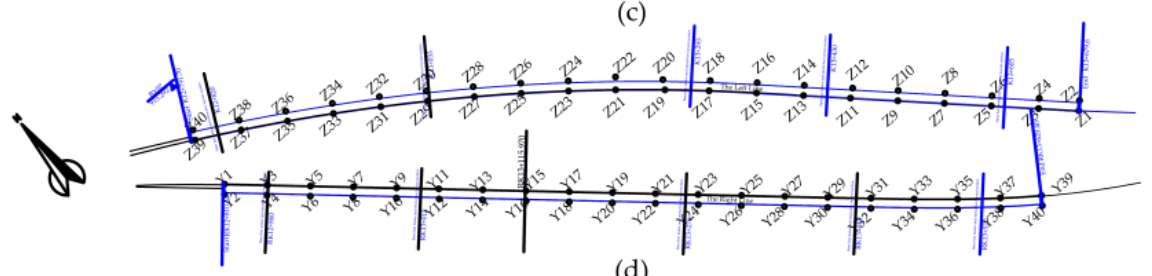

(d)

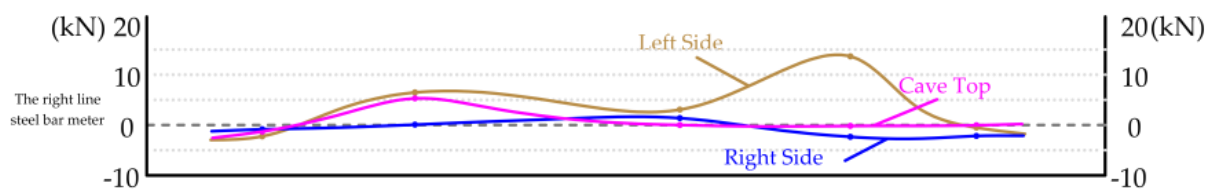

(e)

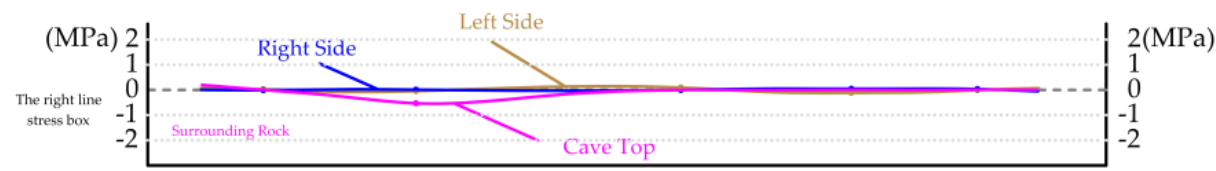

(f)

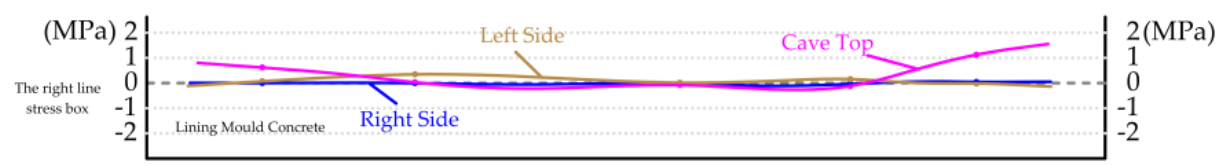

(g)

Legend

in investigation holes tunnel

Figure 12. The observation curve of steer bar meters and stress box. (a) Force of the steel bar meter at the left line. (b) Stress of the stress box in surrounding rock at the left line. (c) Stress of the stress box in lining mould concrete at the left line. (d) Plane layout of stress sensors and rebar stress gauges. (e) Force of the steel bar meter at the right line. (f) Force of the steel bar meter at the right line. (g) Stress of the stress box in lining mould concrete at the right Line. 
From the observed results of the left and right walls and the top of the tunnel, the tensile stress in most sections of the tunnel is at a low level, generally approximately -10 to $20 \mathrm{kN}$ on the left line and -5 to $15 \mathrm{kN}$ on the right line. The maximum value of the rebar stresses gauge was observed only at the left wall in the middle of the left line, and the value was $45 \mathrm{kN}$ (equivalent to $2.69 \mathrm{MPa}$ when converted based on a diameter of $146 \mathrm{~mm}$ ).

The observation results show that the tangential stress in all sections of the tunnel is at a low level, among which the maximum observed tangential stress in the right-line wall rock is $-1.2 \mathrm{MPa}$, and the maximum tangential stress observed in the lining of the left line is $4.2 \mathrm{MPa}$, which is far lower than the shear strength of rock and concrete.

According to the numerical simulation results in the previous stability study, the calculation results show that the normal stress in the radial direction of the tunnel may reach 2 to $4 \mathrm{MPa}$, and the tangential shear stress may reach $\pm 1.5 \mathrm{MPa}$, which is considered insufficient to cause damage to the surrounding rock and lining of the tunnel.

As can be seen by comparing the stability research results and monitoring results of the stress distribution of the surrounding rock, they are both in the same magnitude range, and the difference between them is very small. The actual observed values are also much lower than the shear strength of the rock and the concrete itself. Therefore, the stress distribution of the surrounding rock of the tunnel is in the normal range at the present stage, and the tunnel is in safe operation.

\subsection{Deformation of the Mountain Surface Observation Points}

From the settlement observations of the mountain surface observation points, there is a subsidence in the mountain above the tunnel, and the observation point has undergone displacement both in the horizontal and vertical directions, mainly embodied in vertical displacement (i.e., settlement); the mountain surface observation points above the southeast of the tunnel have experienced a slightly larger settlement, but it is less than $60 \mathrm{~mm}$ and generally uniform.

\subsection{The Stability Evaluation of Tunnel}

The results of monitoring show that the settlement in the goaf has become stable, and the settlement is very small; the maximum inclination of the tunnel surface is $0.05 \%$, so the settlement is uniform on the whole. The subsidence markers at the side walls of both tunnels have all subsided; the accumulative settlement increases from the southeast to the northwest, and the accumulative settlement is consistent with the subsidence trend of the bedrock marker in the goaf, indicating that the settlement of the tunnel side wall is also caused by the subsidence of the goaf. The stress distribution of the surrounding rock of the tunnel is in the normal range at the present stage. Therefore, the tunnel is in safe operation.

\section{Discussions}

It is believed that the main factors affecting the overall stability of the tunnel include the vertical displacement (settlement) of the road surface, the horizontal displacement of the tunnel wall, the stress distribution of the tunnel wall, the category of the surrounding rocks of the tunnel, the geological structure conditions, and the "activation" factors of the goaves. The residual settlement in the goaf in the study area was predicted and analyzed [33], and the deformation and displacement were forecasted. The stress distribution of the tunnel wall is caused by the large change in the deep bedrock marker deformation, the engineering geological stability of the study area was comprehensively analyzed and evaluated, and the stability of the tunnel was predicted and evaluated by considering the above factors.

The recently related research on highway structures passing through coal mine goaves include the research on the coal goaf's impact on the route selection of Xuzhou Huancheng Expressway conducted by Tong [2,3] from the Southeast University, which focused on the relevant impacts of coal mine goaves on highway cutting and subgrades in southern China as well as the corresponding control measures. Most of the above-mentioned research is mainly based on qualitative analysis, and the deformation fortification level of the 
local structure is low. The assessment and analysis of this project adopted a combination of quantitative and qualitative evaluation methods, and the structures (medium-long highway tunnels) affected by the goaves of the coal mines are sensitive to deformation.

In this study, due to the limited scope of the study area, the engineering mechanical deformation characteristics of the caving rock masses in the multi-layer goaf were analyzed in the process of numerical simulation. Considering that there is little difference in the direct roof lithology of the coal seam, the caving rock masses in the goaf were defined as the caving engineering geological type, so as to comprehensively simulate the deformation on the tunnel floor caused by the influence of the multi-layered goaf. In future studies, if there is a significant difference in the direct roof of the multi-layer goaf and the engineering properties of the goaf in each layer vary greatly, then the different fractured engineering geological types can be defined for numerical simulation analysis.

In this study, bedrock monitoring targets and base rock observations were built for the roofs of different goaves in the same section. As of 9 March 2015, the bedrock markers' subsidence was more uniform compared with that of the reference points, and generally, the sediment was small in the southeast and large in the northwest. Despite the differences in the settlement of the goaves at different locations, the subsidence rates of the monitoring points at different depths in all groups are basically the same, and the residual settlement of the tunnel site is mainly derived from the goaf of seam no. 15 . The goaf of seam no. 15, with features of great mining thickness, late mining, and deep burial, has a controlling effect on the settlement of the site, and the settlement of the above layers of goaves is basically "absorbed" by this layer. When the research scope is relatively large and the deformation characteristics of the goaf of the lower layers are different in space, the layered goaf monitoring system can predict the later overall deformation of the upper part according to the monitoring data of the lower part of the layer, to play an early warning role and forecast the occurrence of geological disasters.

A comprehensive monitoring system was used in this study, including the subsidence deformation monitoring of multi-layer sublevel discontinuities, tunnel subsidence deformation monitoring, tunnel rock stress monitoring, and subsidence deformation monitoring of the upper mountain body, and certain improvements were made compared with other previous projects that adopted only a single ground deformation monitoring method. The use of this comprehensive monitoring system will facilitate the analysis and processing of relevant engineering geological problems on a similar project.

\section{Conclusions}

The three-dimensional monitoring of the layered subsidence deformation of the goaf at the bottom of the tunnel, the deformation of the sidewall of the tunnel, the stress of the surrounding rock of the tunnel and the deformation of the top of the mountain, and mutual verification between the monitoring results were achieved.

The subsidence deformation of the lower four-layer goaves was observed in layers, the settlement rate of the deep bedrock markers was higher than that of the shallow ones, and the possible deformation of the tunnel floor was forecasted in advance based on the observed subsidence deformation of the monitoring target points. At the same time, the settlement of the side walls of the tunnel was observed, the stress in the tunnel surrounding the rock loosening zone circle was measured, and the deformation of the mountain above the tunnel portal was measured for many years; the monitoring results were compared with the stability prediction and evaluation results; and it was shown that the current tunnel deformation values are within the scope of the prediction and assessment, indicating that the tunnel is in safe operation.

If the tunnel surface maximum inclination or the deep bedrock marker plane inclination is up to 1\% [34], it will harm the structure on this area. Therefore, important projects should avoid goaves or be constructed after comprehensive evaluation and more monitoring. 
Author Contributions: Conceptualization, W.S., G.C. and S.W.; Formal analysis, J.C.; Investigation, G.C.; Methodology, G.C. and S.W.; Project administration, J.W.; Supervision, W.S. All authors have read and agreed to the published version of the manuscript.

Funding: The research of this project was supported by the "Geological stability evaluation and monitoring study of the Tianzimiao tunnel at 307 National Highway Double-line Tianzimiao Tunnel" (grant number: KY2007005), and the Shanxi Provincial University Science and Technology Development Project of "Study on the Formation Mechanism and Regularity of Surface Settlement Geological Disasters" (grant number: 20041250).

Acknowledgments: Helps from the Yangquan Hongda Highway Management Co., Ltd., Shanxi Jiaoke Highway Survey, Design Institute Yangquan Branch, Ding Chenjian, Chen Yimin, Zhang Ruizheng, Zhang Yun are appreciated.

Conflicts of Interest: The authors declare no conflict of interest.

\section{References}

1. Li, J.M.; Yu, J.H.; Zhang, W.Z. Spatial distribution and governance of coalmine subsidence in China. J. Nat. Resour. 2019, 34, 867-880.

2. Tong, L.Y.; Liu, L.; Yu, Q. Highway construction across heavily mined ground and steep topography in southern China. Bull. Eng. Geol. Environ. 2014, 73, 43-60. [CrossRef]

3. Tong, L.; Leo, L.; Amatya, B.; Liu, S. Risk assessment and remediation strategies for highway construction in abandoned coal mine region: Lessons learned from Xuzhou, China. Bull. Eng. Geol. Environ. 2015, 75, 1045-1066. [CrossRef]

4. Chen, L. Experimental Study of Analog Simulation on Stability Analyse of Bridge and Tunnel with Underlying Goaf during Expressway. Master's Thesis, Taiyuan University of Technology, Taiyuan, China, 2008.

5. Liu, T. Grouting Study of the under Gob of Tai-Jia Freeway. Master's Thesis, Northwest University, Xi'an, China, 2010.

6. Dong, X.B.; Rao, X.; Guo, L.C. Deformation analysis and treating measures to gob areas of coal mine under freeway. J. Xi'an Univ. Sci. Technol. 2009, 26, 697-701.

7. Zhao, J.G. Stability Evaluation of the Goaf Underlying Tai-Jia Highway. Master's Thesis, Northwest University, Xi'an, China, 2010.

8. Tong, L.Y.; Qiu, Y.; Du, G.Y.; Huang, W.; Liu, S.Y. Field testing of grouting method treating multilayer mined-out region under expressway. J. Highw. Transp. Res. Dev. 2002, 19, 19-27.

9. Yang, W.X. Investigation and Treatment of Goaf in Coal Mine under Expressway. Master's Thesis, Chang'an University, Xi'an, China, 2005.

10. Zhao, C. Numerical Simulation Analysis and Stability Evaluation of Tunnel Surrounding Rock under Mined-Out Areas. Master's Thesis, Taiyuan University of Technology, Taiyuan, China, 2011.

11. Li, J.W.; Feng, S.W.; Zhou, Y. Mechanical mechanism of surrounding rock catastrophe evolution during construction of tunnel under goaf. Zhongnan Daxue Xuebao (Ziran Kexue Ban) 2021, 52, 543-554.

12. Huang, Q. Surrounding rock stress analysis of sequential mining method. In Proceedings of the 2011 International Conference on Remote Sensing, Environment and Transportation Engineering, Nanjing, China, 24-26 June 2011; pp. 5445-5448.

13. Zou, Y.F.; Deng, K.Z.; Ma, W.M. Mining Subsidence Engineering; China University of Mining and Technology: Xuzhou, China, 2003; pp. 54-68.

14. Guo, G.L.; Deng, K.Z.; Tan, Z.X.; Li, F.C. Study on the prediction method of ground residual subsidence in the deep abandoned longwall goaf and its application. J. Liaoning Tech. Univ. (Nat. Sci. Ed.) 2002, 21, 1-3.

15. Zhang, H.Z.; Deng, K.Z.; Tan, Z.X. Study of abandoned mine goaf residual movement and deformation. Ground Press. Strat. Control. 2005, 1, 32-34.

16. Jang, M.; Yang, H.S.; Chung, S.K. Stability analysis of high speed railway tunnel passing through the abandoned mine area. In Proceedings of the 9th ISRM Congress, Paris, France, 25-28 August 1999; pp. 181-183.

17. Li, X.Y.; Li, J.P.; Zhou, C.B. Comparative study on numerical simulation and similarity simulation of over burden deformation in abandoned stope. Rock Soil Mech. 2005, 26, 1907-1912.

18. Zhang, Z.P.; Wang, Z.Y.; Liu, X. Long term stability between freeway and gob of coalmine. J. Xi'an Univ. Sci. Technol. 2005, 25, 415-419.

19. Wang, S.J.; Jia, X.M.; Han, W.F.; Cui, S.M. A FLAC3D method for calculation of residual subsidence in a mining area beneath an expressway. Chin. J. Rock Mech. Eng. 2005, 24, 3545-3550.

20. Qiao, D.P.; Zhang, Z.S.; Wang, S.H.; Zhang, Y. Numerical modelling and assessment of excavation damaged zone around the underground excavations: A case study. Key Eng. Mater. 2006, 324-325, 77-80. [CrossRef]

21. Alejano, L.R.; Ramirez-Oyanguren, P.; Taboada, J. On the paper FDM predictive methodology for subsidence due to flat. Int. J. Rock Mech. Min. Sci. 1999, 36, 475-491. [CrossRef]

22. Xie, H.P.; Zhou, H.W.; Wang, J.A. Application and contrasting analysis of FLAC3D in prediction subsidence of coalmining. Chin. J. Rock Mech. Eng. 1999, 18, 397-401. 
23. Yin, S.X. Numerical simulation of influence of water barrier pillars for subsided column on rock failure in mining process. J. China Coal Soc. 2006, 31, 179-182.

24. Hou, Z.Y.; Wang, J.C. Numerical simulation of surface subsidence on the conditions of "three-hard" in Datong mining area. J. China Coal Soc. 2007, 32, 235-238.

25. Li, Z.G. Stability analysis and reinforcement technology of mined-out area in Tieshan tunnel. Chin. J. Rock Mech. Eng. 2002, 21, 1168-1173.

26. Cui, X.M. Improved prediction of differential subsidence caused by underground mining. Rock Mech. Min. Sci. 2000, 37, 615-627. [CrossRef]

27. Donnelly, L.J. The monitoring and prediction of mining subsidence in the Amaga, Angelopolis, Venecia and Bolombolo Regions Antioquiat Colombia. Eng. Geol. 2001, 59, 103-114. [CrossRef]

28. Teng, Y.H. Evaluation on stability of building foundation over goafs. J. China Coal Soc. 1997, 22, 504-508.

29. Yu, Y.H. Prediction analysis of high class highway influenced by surface residual deformation in mining zones. J. Xi'an Highw. Univ. 1997, 21, 9-12.

30. Tong, L.Y. Research on the Interaction between Highway and Mined-Out Region and Its Improving Techniques. Ph.D. Thesis, Southeast University, Nanjing, China, 2003.

31. Tong, L.Y.; Liu, S.Y.; Qiu, Y.; Lei, F.G. Current research state of problems associated with mined-out regions under expressway and future development. China J. Rock Mech. Eng. 2004, 23, 1198-1202.

32. Tong, L.Y.; Liu, S.Y. Hazard. Evaluation and Treatment Technology of Goaf under Expressway; Southeast University: Nanjing, China, 2006; pp. 6-18.

33. Ding, C.J. Study on Character and Forecast Model of Residual Deformation in Mining Site. Ph.D. Thesis, China University Mining \& Technology, Xuzhou, China, 2009.

34. GB. 51044-2014. Code for Investigation of Geotechnical Engineering in Coal Mine Goaf; China Planning Press: Beijing, China, 2017. 